Illinois State University

ISU ReD: Research and eData

Theses and Dissertations

7-13-2021

\title{
"How Do I Make Them Understand and Then Why Would I?" Exploring the Impact of Disclosure and Support on Coping Perceptions Among Nurses With Their Families
}

Madeline Katherine Witt

Illinois State University, madelinewitt15@augustana.edu

Follow this and additional works at: https://ir.library.illinoisstate.edu/etd

\section{Recommended Citation}

Witt, Madeline Katherine, "'How Do I Make Them Understand and Then Why Would I?" Exploring the Impact of Disclosure and Support on Coping Perceptions Among Nurses With Their Families" (2021). Theses and Dissertations. 1478.

https://ir.library.illinoisstate.edu/etd/1478

This Thesis is brought to you for free and open access by ISU ReD: Research and eData. It has been accepted for inclusion in Theses and Dissertations by an authorized administrator of ISU ReD: Research and eData. For more information, please contact ISUReD@ilstu.edu. 


\section{“HOW DO I MAKE THEM UNDERSTAND AND THEN WHY WOULD I?" EXPLORING THE IMPACT OF DISCLOSURE AND SUPPORT ON COPING PERCEPTIONS AMONG NURSES WITH THEIR FAMILIES}

\section{MADELINE KATHERINE WITT}

\section{Pages}

Nurses play a central part of healthcare in modern Western medicine, often taking on various roles and acting as liaisons in a multitude of situations. Especially in regard to the most recent global health crisis, COVID-19, more attention has been paid to the ways in which nurses handle the stress of the job. With the establishment of Cutrona and Suhr's (1994) five categories of social support and Lazarus and Folkman's (1987) Transactional Model of Stress and Coping, research has been able to address the role of social support in the coping process; however, little attention has been paid to the ways in which nurses manage privacy and disclosure with their family members to garner support and cope. This study aimed to better understand how nurses navigate privacy and disclosure regarding their work-related experiences with family members to receive social support and cope. In-depth, semi-structured interviews were conducted with 20 participants who were currently practicing registered nurses. Through analysis, responses were categorized utilizing Cutrona and Suhr's (1994) categories of social support and Lazarus and Folkman's (1987) Transactional Model of Stress and Coping. In addition, Petronio’s (2002) Communication Privacy Management (CPM) theory was used as a framework to highlight the parts of the theory that were most salient in the privacy management behaviors among participants and their family members. Participants demonstrated several social support and 
coping strategies. Additionally, many nurse-specific privacy management themes emerged, demonstrating the benefit of exploring the experiences of nurses and their families through the lens of CPM. Implications of the study, limitations, and future research are then discussed.

KEYWORDS: Nurses, Communication Privacy Management Theory, Family Communication, Disclosure, Social Support, Coping, Stress, COVID-19 
“HOW DO I MAKE THEM UNDERSTAND AND THEN WHY WOULD I?” EXPLORING THE IMPACT OF DISCLOSURE AND SUPPORT ON COPING PERCEPTIONS AMONG NURSES WITH THEIR FAMILIES

MADELINE KATHERINE WITT

\author{
A Thesis Submitted in Partial \\ Fulfillment of the Requirements \\ for the Degree of \\ MASTER OF SCIENCE \\ School of Communication \\ ILLINOIS STATE UNIVERSITY
}


(C) 2021 Madeline Katherine Witt 
“HOW DO I MAKE THEM UNDERSTAND AND THEN WHY WOULD I?” EXPLORING THE IMPACT OF DISCLOSURE AND SUPPORT ON COPING PERCEPTIONS AMONG NURSES WITH THEIR FAMILIES

MADELINE KATHERINE WITT

COMMITTEE MEMBERS:

Aimee E. Miller-Ott, Chair

Lance Lippert

Lindsey Thomas 


\section{ACKNOWLEDGMENTS}

First and foremost, I could not have achieved this accomplishment without the support of my family. Thank you for being the most consistent cheerleaders in my life, celebrating all of my smallest wins and encouraging me even when I've been at my lowest of lows. I can't even begin to describe the impact that has had on my personal growth and academic success. And to the biggest cheerleader of them all, mom, thank you for being a huge source of love and light in my life. Thank you for every late-night phone, card in the mail, and encouraging message. You believed in me when I didn't believe in myself, and I am so grateful for you.

Additionally, I would like to thank my incredible committee. To Dr. Lippert, thank you for always challenging me to make everything I learn accessible and applicable. Your constant encouragement to go beyond the textbook and find the humor in everything are things that I will take beyond my academic career. To Dr. Thomas, thank you for showing me that learning is a life-long process. Your family communication course served as a huge inspiration for my thesis, giving me the foundation to look for the nuances in everything. Your academic expertise, as well

as your ability to make academia relatable are things that I am so grateful for. And finally, to Dr. Miller-Ott, thank you for your constant support and patience as I navigated this process. At times, I wasn't sure if I would finish, but your support never faltered. Thank you for encouraging me to listen to my intuition and believe in my academic abilities.

Although I will never be able to fully thank everyone that made this possible, I am so grateful to every friend, family member, teacher, mentor, therapist, and buddy that has supported me and helped me along the way.

M.K.W. 


\section{CONTENTS}

Page

ACKNOWLEDGMENTS

CHAPTER I: INTRODUCTION 1

CHAPTER II: REVIEW OF LITERATURE

$\begin{array}{ll}\text { Nursing Stressors } & 4\end{array}$

High Demand and Job Turnover in Nursing 4

Emotional Toll on Nurses $\quad 5$

$\begin{array}{lr}\text { Compassion Fatigue } & 6\end{array}$

$\begin{array}{ll}\text { Burnout } & 7\end{array}$

Nurses' Coping with the Job 9

Social Support $\quad 11$

$\begin{array}{ll}\text { Coworker Support } & 12\end{array}$

$\begin{array}{ll}\text { Family Support } & 14\end{array}$

$\begin{array}{ll}\text { Communal Coping } & 16\end{array}$

$\begin{array}{ll}\text { Communication Privacy Management Theory } & 18\end{array}$

$\begin{array}{ll}\text { Suppositions of CPM } & 18\end{array}$

$\begin{array}{lr}\text { Rule-based Management System } & 20\end{array}$

Privacy Management among Family Members $\quad 22$

$\begin{array}{ll}\text { CHAPTER III: METHODS } & 27\end{array}$

$\begin{array}{ll}\text { Participants } & 27\end{array}$

$\begin{array}{ll}\text { Procedures } & 28\end{array}$

$\begin{array}{ll}\text { Data Analysis } & 30\end{array}$ 
Topics Discussed

Medical Situations

Vague Patient Stories

Updates about COVID-19

Management Issues

Family Medical Wishes

Topics Avoided

Identifying Patient Information

Graphic and Heartbreaking Parts of the Job

Specific Details about COVID-19

Specific Medical Terminology

Advice about Topic Disclosure and Avoidance

Communication Privacy Management Theory

Privacy Rule Foundations

The Relationship with the Family Member

Recipient Knowledge Level

Recipient Medical Experiences

Recipient Comfort Level with Medical Scenarios

Worrying Family Members

Protecting Family Members 
Recipient Responses $\quad 52$

Boundary Coordination and Boundary Turbulence 53

Advice about Managing Private Information with Family Members 57

$\begin{array}{ll}\text { Forms of Social Support } & 58\end{array}$

$\begin{array}{lr}\text { Action-Facilitating Support } & 59\end{array}$

$\begin{array}{ll}\text { Informational Support } & 59\end{array}$

$\begin{array}{ll}\text { Tangible Aid } & 60\end{array}$

$\begin{array}{ll}\text { Monetary Support } & 60\end{array}$

$\begin{array}{ll}\text { Household Tasks } & 60\end{array}$

$\begin{array}{ll}\text { Child Care } & 61\end{array}$

$\begin{array}{ll}\text { Nurturing Support } & 62\end{array}$

$\begin{array}{ll}\text { Emotional Support } & 62\end{array}$

Impact of COVID-19 on Support 62

Advice about Forms of Social Support 64

Impact of Social Support on Coping $\quad 64$

Transactional Model of Stress and Coping 66

Emotion-Focused Coping 66

$\begin{array}{ll}\text { Positive Appraisal } & 66\end{array}$

$\begin{array}{ll}\text { Seeking Social Support } & 67\end{array}$

$\begin{array}{ll}\text { Social Support Did Not Impact Coping Ability } & 68\end{array}$

Advice about the Impact of Social Support on Coping 70

$\begin{array}{ll}\text { CHAPTER V: DISCUSSION } & 71\end{array}$ 
$\begin{array}{ll}\text { Summary of Findings } & 71\end{array}$

$\begin{array}{ll}\text { Research Implications } & 77\end{array}$

$\begin{array}{ll}\text { Recipient Boundary Coordination } & 77\end{array}$

$\begin{array}{ll}\text { The Relationship Between Sharing and Coping } & 79\end{array}$

Absence of Communal Coping $\quad 81$

Advice for Nurses, Family Members, and Healthcare $\quad 82$

Limitations and Future Directions $\quad 85$

$\begin{array}{ll}\text { Conclusion } & 86\end{array}$

$\begin{array}{lc}\text { REFERENCES } & 88\end{array}$

APPENDIX A: EMAIL RECRUITMENT 101

APPENDIX B: SOCIAL MEDIA RECRUITMENT POST 102

APPENDIX C: INFORMED CONSENT 103

$\begin{array}{ll}\text { APPENDIX D: PRE-INTERVIEW QUESTIONNAIRE } & 105\end{array}$

APPENDIX E: INTERVIEW PROTOCOL 106 


\section{CHAPTER I: INTRODUCTION}

Nurses play a central part of healthcare in modern Western medicine, often taking on various roles and acting as liaisons in a multitude of situations. They are described as primary caregivers, expected to provide emotional support for patients and families as well as coordinate the care of patients. In the early eighties, the hospital nurse was considered the "physician's hand," serving as a caregiver, teacher, and emotional support for the patients and families (Melosh, 1982). The duties of nurses have expanded past that, with tasks now including collaborating with physicians, interacting with health personnel, supervising assistant personnel, and leading coordination across the healthcare field (Miller \& Apker, 2002; Miller et al., 2000). Nurses in intensive-care units (ICUs) serve as confidants for families, build rapport, and keep an open line of communication with family members due to their inability to visit the hospital (Montauk \& Kuhl, 2020). The nursing role is continually being negotiated and renegotiated within the work environment. Nurses, in sum, must be viewed as professionals who invest in and sustain various relationships to ensure quality care for patients (Apker et al., 2005).

The COVID-19 pandemic has also led to additional responsibilities for nurses. Public health nurses are on the frontline of the COVID-19 pandemic. They serve on mobile teams evaluating case-contacts, educating about isolation, and interpreting the ever-changing guidelines stated by the Center for Disease Control and Prevention (CDC) (Edmonds \& Campbell, 2020). The constant addition of new roles and responsibilities, as well as the consistent need to provide emotional support for patients, makes the nursing role a balancing act.

The COVID-19 pandemic has also impacted the livelihood of nurses around the world. Nurses who are working with COVID-19 patients daily are not only at higher risk for contracting the disease but also for experiencing psychological issues as a result of their work (Huang et al., 
2020). A cross-sectional study conducted in Hubie, China identified significantly high rates of mental health symptoms in nurses during the pandemic, including moderate to severe traumarelated stress, depression, anxiety, and insomnia (Lai et al., 2020). Nurses are currently working under constant physical and emotional pressure, putting their lives at risk while fulfilling their work-related responsibilities (Catton, 2020). In addition to work-related distress, nurses have to confront the reality of possibly infecting their loved ones or being isolated from them to keep them safe (Huang et al., 2020).

It is evident in the research done during times of crisis prior to 2021, like the severe acute respiratory syndrome (SARS) outbreak and the $9 / 11$ terrorist attacks, that the mental health impact on first responders is substantial and worth discussing. There were a multitude of studies that addressed the psychological impact of the 2002-2003 SARS outbreak in Asia and Canada. Health care workers in both Toronto and Hong Kong experienced significant levels of stress during the outbreak due to changing conditions, feelings of isolation, and concerns with infecting their loved ones (Maunder et al., 2003; Wong et al., 2005). In addition, Bai et al. (2004) found that health workers directly working with SARS patients reported higher rates of fear, vulnerability, and other symptoms of disorders related to trauma. Even after the outbreak, Toronto health care workers who provided care to SARS patients reported higher levels of burnout, emotional distress, and trauma-induced stress (Maunder et al., 2006). Similar findings occurred in research done about the 9/11 terrorist attacks in the United States. First responders and recovery workers with higher exposure to the attacks experienced symptoms related to posttraumatic stress disorder (PTSD), as well as higher rates of functional impairments four years after (Neria et al., 2011). It is likely that these findings can apply to nursing during the current pandemic situation. 
The well-being of all aspects of the health care system in dependent on the well-being of healthcare professionals (Moss et al., 2016). Thus, it is important to consider that ways in which nurses cope with the stressors of the job. While previous research indicates that many nurses rely on social support in times of crisis (Özçevik et al., 2021), it does not explore the idea that some nurses may not ask for support. In addition, previous research does not explore the potential role that privacy and disclosure plays in the coping process. The ever-expanding role of nurses, as well as the consistent distress under which they are put under, leads to the present study.

This study seeks to better understand how nurses manage information regarding their work-related experiences with family members in hopes of understanding how nurses navigate privacy and disclosure to garner support and cope with their job. In this thesis, I will outline previous research conducted on nursing stressors, social support in the context of coping, and privacy management within families before thematically analyzing transcripts of semi-structured interviews to determine how nurses and families communicatively navigate privacy management, social support, and the coping process. 


\section{CHAPTER II: REVIEW OF LITERATURE}

This review of literature gives an overview of the stressors that impact nurses before focusing on their coping behaviors and how they seek out social support. An overview of communal coping precedes an examination of communication privacy management theory. Once I have provided the theoretical basis, specifically how privacy is salient in the nursing field and how privacy management occurs among family dealing with crisis, I will lead into the research questions of this study. The purpose of this study is to better understand the privacy management tendencies among nurses with their families in hopes of understanding how privacy and disclosure impact social support and the coping process.

\section{Nursing Stressors}

\section{High Demand and Job Turnover in Nursing}

The United States has experienced nursing shortages in a cyclical nature for years, first being documented in the 1950s (Egenes, 2012). When staff shortage becomes frequent, remaining nurses can become fatigued and discouraged, often feeling like they must take shortcuts in patient care or not finish all of their daily responsibilities due to work overload (Lake et al., 2017). Currently, The Bureau of Labor Statistics (2021) states that the "employment of registered nurses is projected to grow $7 \%$ from 2019 to 2029.” The demand for nurses will continue to grow, especially with the growing population of aging adults and the current COVID-19 crisis (Nursing Journal, 2021). In addition, the demand for nurses in various settings, including residential care facilities and rehabilitation centers, will increase because of the aging population's need for long term care (Bureau of Labor Statistics, 2021). However, the national average for nurse turnover rates in the United States is $8.8 \%$ to $37 \%$ depending on location and specialty (Haddad et al., 2020). Nurse turnover rates negatively impact quality of patient care 
due to a higher nurse-to-patient ratio (Castle \& Engberg, 2006). For example, if a nurse leaves an organization, the remaining nurses need to distribute the patients from the nurse who left until someone new is both hired and onboarded. O'Brien-Pallas et al. (2010) reported that higher nurse turnover rates, as well as role ambiguity, can generally increase medical error. When high turnover is present in an organization, nurses must treat more patients than usual to make up for lost staff, stretching their roles thin and adding more responsibilities to their plates.

\section{Emotional Toll on Nurses}

In addition to job expectations, even amid staff shortages, nurses are expected to commit emotionally to their job and to their patients. Emotional labor refers to an employee's display of emotions that are necessary to accomplish the goals of the organization (Hochschild, 2012).

Originally intended to explore the commercialization of emotions, Hochschild (1983)

investigated how women flights attendants gave their airline a competitive edge using emotional labor. By prescribing the display of specific emotions, the organization determines what emotions are respectable and accepted in the workplace (Hochschild, 2012). For example, flight attendants are expected to be warm and positive to guests, ready to serve them throughout the entirety of their flight experience. Since emotional expression is predetermined by the organization, the voice of the organization may come before the voice of the individual worker. Hochschild (1983) argues that the management of emotion can vary based on the worker's status, power in the organization, and type of service in which they work. Since scholars created the term emotional labor, researchers have used the term to explain the practice and the impact of emotional management on individuals in various professions, including teachers (Yao et al., 2015), hotel employees (Lee \& Ok, 2012), and nurses (Karimi et al., 2014). While certain 
individuals do not experience personal repercussions from emotional labor, problems may occur when an individual has increased contact with situations in which emotions run high.

Some employees may experience emotional dissonance when there is inconsistency in how they feel versus how they display their feelings based on the organizational expectations (Hochschild, 2012). For example, Conte (2014) found that nurses often suppress their own emotions after experiencing loss at work to continue working with other patients during their shifts. Nurses engage in tactics to manage their emotions based on the standards set by the organization. Hochschild (2012) discusses that there are two forms of emotion management: surface acting and deep acting. Surface acting happens when an individual disguises their feelings by showing the emotion that is expected of them. On the other hand, deep acting occurs when an individual completely restructures their perception of a specific situation and deceives themselves into expressing what is deemed to be the correct emotion. Having to actively manage emotions to fit into a specific set of rules set by the organization amidst a crisis may lead to various problems, such as high turnover rates (Leiter \& Maslach, 1988) and employee burnout (Kowalski \& Vaught, 2001), which likely occurs with nurses during the COVID-19 pandemic and other high-stress work times. Due to the emotional labor present within the nursing field, nurses may also experience compassion fatigue.

\section{Compassion Fatigue}

Compassion fatigue occurs when nurses have consistent contact with patients and exposure to stress over an extended period without implementing coping strategies to alleviate any of the pressure (Coetzee \& Klopper, 2010). Compassion fatigue, a form of exhaustion, describes the personal impact that close investment and stress exposure can have on a nurse's psyche. Symptoms of compassion fatigue include depression, emotional burnout, post-traumatic 
stress disorder (PTSD), and deep feelings of despair (McCloskey \& Taggart, 2010; Whitebird et al., 2013). In many instances, nursing staff are expected to resume their normal work schedules immediately after the deaths of their patients, not allowing them time to grieve, which can add to their compassion fatigue (Wakefield, 2000). Compassion fatigue can decrease nurses' job performance and increase mistakes, hurt their relationships, and lead to significant declines in health (Perry et al., 2011). In addition, nurses can feel isolated and unable to share their feelings when a patient dies, which can lead to the perception of inadequate support and ultimately a decision to leave their careers (Papadatou, 2000; Shinbara \& Olsen, 2010). While compassion fatigue is specific to a nurse's encounter with patient experiences, being immersed in the particular work environment can lead to burnout among nurses.

\section{Burnout}

The concept of burnout in a healthcare setting was developed in the 1960s to describe the emotional and psychological stress experienced by medical staff when caring for patients (Freudenberger, 1974). Scholars and practitioners have used the term burnout to describe stress experienced by staff in various health-related work environments, from specific hospitals to global health environments (Kim et al., 2018). Maslach et al. (1986) further defined burnout by describing it as "a psychological syndrome of emotional exhaustion, depersonalization, and reduced personal accomplishment that can occur among individuals who work with other people in some capacity" (p. 192). Researchers argued that the first key element of burnout is a worker's increase in emotional exhaustion that causes their inability to exert any psychological energy. The second aspect of burnout, depersonalization, involves a worker having cynical attitudes toward clients, sometimes believing that the client deserves what has come their way. Lastly, 
reduced personal accomplishment is a worker's tendency to view themselves negatively, which includes disregarding their accomplishments and positive interactions with their clients.

The factors that often contribute to nurse burnout include amount of workload, moral distress, lack of quality support systems, and bullying (Marais et al., 2016; Rushton et al., 2015). Nurses may encounter one or more of these factors within their work environment. The consistent turnover, inexperienced staff, and higher nurse-to-patient ratio can contribute to higher workload in nurses (Marais et al., 2016). In turn, workload can impact a nurse's perception of their personal accomplishments, making them feel as though they are unable to take care of their patients properly (Dolan et al., 2012; Tubbert, 2016). Another factor, moral distress, occurs when a nurse recognizes a moral problem, acknowledges some form of responsibility for it, and makes a judgement about the best way to confront it; however, as a result of circumstance, the nurse may participate in a behavior that is morally wrong (Nathaniel, 2002). In addition, specific ethical dilemmas within the hospital setting impact the levels of moral distress that nurses feel. For example, nurses may find themselves having to decide which patients are more worthy of a ventilator in the case of resource shortage as they have experienced during the COVID-19 pandemic. If one patient is critical and unlikely to survive and the other is less critical with a higher chance of survival, who should receive the ventilator? Nurses may find themselves in situations like these every day, never being sure what the "right" decision is. Rushton et al. (2015) argued that moral distress increases the likelihood of nurses leaving their jobs. Lack of quality support systems within the hospital can impact nurse burnout as well. Due to both inexperience and larger nurse-to-patient ratio, nurses are not always available to support one another in times of distress (Potter et al., 2013). In addition, the conflict present among coworkers can stem from elevated levels of stress or even inability to form relationships due to 
the complex nature of the existing work environment (Dolan et al., 2012; Marais et al., 2016). Because of the immense stress that nurses experience on a daily basis, particularly in times of crisis as they are now, it is important to consider how they cope with particular stressors.

\section{Nurses' Coping with the Job}

The well-being of every aspect of the health care system is dependent on the well-being of the healthcare professionals (Moss et al., 2016). It is important to consider how nurses cope with various stressors due to their vital role within the health care system. In the transactional model of stress and coping, Lazarus and Folkman (1987) explain that coping has two central functions: to change the terms of the problematic person-environment relationship (problemfocused coping) and to manage emotional distress (emotion-focused coping). Individuals utilize both functions in practically every stressful situation and engage in various actions (e.g. distancing, seeking social support, accepting responsibility, or positive reappraisal) to cope (Lazarus \& Folkman, 1987).

Nursing staff implement several coping strategies, at both personal and group levels, to manage general stress of the job and symptoms of compassion fatigue and burnout. Finding activities and practices that replenish, revitalize, and generally comfort nurses is an important part of managing general stress and compassion fatigue (Bush, 2009). Wei et al. (2020) interviewed nursing staff to obtain an in-depth understanding of self-care strategies nurses use to combat burnout. They found that nurses practice five major self-care practices: finding meaning in their work, connecting with an energy source, performing emotional hygiene, noticing one's uniqueness, and nurturing their interpersonal relationships. The first four of these strategies reflect individual coping behaviors, and the last strategy reflects group coping behaviors, which will be discussed more in-depth later in this chapter. Gray and Kim (2017) found that when care 
workers experienced loss of a patient, they coped by keeping busy and creating mental checklists. Self-care practices provide an opportunity for nurses to emotionally, mentally, and physically recharge, which gives them the energy to provide quality care for patients, socially support their coworkers, and combat burnout (Gray \& Kim, 2017). In addition, specifically for caretakers at nursing homes, humor exchanges are used as a way for caretakers and patients to deal with the sometimes-depressing nature of the work-environment, as well as avoid creating interactions that could become too somber (Lippert \& Hunt, 2005). While these individual strategies may address how nurses cope during "normal" times, they do not address the coping strategies used by nurses during times of crisis.

Coping may look different during times of high stress. For instance, nurses reported coping with SARS-related stressful situations during the 2003 SARS outbreak differently compared to their typical daily stressful situations (Gan et al., 2004). They responded to SARSrelated events with diminished ability to assess the controllability of situations and with significantly inconsistent coping strategies. Due to the comparability between the SARS outbreak and the COVID-19 pandemic, the assumption can be made that nurses are currently coping with stress differently compared to non-pandemic times; however, there is limited research that identifies how nurses have coped during COVID-19. One study by Suryavanshi (2020) found that nurses have implemented relaxation practices like doing yoga, reading, and watching movies during the COVID-19 pandemic. In addition, Özçevik et al. (2021) found that in Turkey, healthcare workers relied on seeking social support as the most common coping strategy during the pandemic. Thus, while individual coping strategies can help nurses manage the stressors of their job, it is important to note that coping can also happen when nurses seek 
support from others. In the following section, I describe previous scholarship on social support, as well as how social support can impact how nurses cope with job-related stressors.

\section{Social Support}

Having opportunities to discuss difficult emotions with others (typically other nursing staff) and receive support can help nurses to realize that their feelings are common and valid (Lally, 2005). Social support involves behaviors that are used to persuade individuals that they are valued and care for that enhance their ability to cope with challenges (Cutrona \& Suhr, 1994). While scholars have conceptualized types of social support in a variety of ways, Cutrona and Suhr (1994) identified five major categories that reflect the intersection of previous research. These categories are designated to two overarching categories: action-facilitating support and nurturing support. Action-facilitating support includes behaviors that assist another individual in managing their daily tasks such as running a quick errand or finding informative resources. Under the umbrella of action-facilitating support are informational support, which entails providing facts, advice, or information referrals; and tangible aid, which reflects services provided to improve a situation (e.g., driving someone to the hospital). Nurturing support involves communicating messages that acknowledge the other person's emotions, providing companionship, and helping build self-esteem. Nurturing support includes esteem support, which entails giving positive comments to validate someone's self-concept; network support, which involves connecting someone with others who are dealing with similar situations; and emotional support, which refers to validating someone's feelings through heartfelt expressions. The functions of social support can be best explained in the stress-buffering social support model.

According to the stress-buffering model, social support provides emotional protection to individuals from the damaging effects of stressful events and helps them adapt to coping 
behaviors (Cobb, 1976). Specific to the study of actions of social support after stressful events in college students, Cutrona (1986) found that students most frequently received both emotional support (listening and expressing care) and informational support (offering advice and expressing perspective of the problem) from their peers. Furthermore, students who received the greatest number of these helping behaviors reported the highest levels of perceived social support and were less depressed following the stressful events. Because various expressions of social support received following stressful life events can promote adaptive coping (Cobb, 1976), it is important to understand the types of social support present within the lives of nurses, especially during the COVID-19 pandemic. In investigating how nurses receive social support from others, we can better understand how they cope with the stress of their job.

Among nurses, social support, whether it comes from the supervisor, the organization, or a spouse, has been found to impact burnout, overall job satisfaction, life satisfaction, and levels of depression (Yildirim \& Aycan, 2008). More specifically, hospital nurses who receive high levels of social support from colleagues and family members have lower levels of both burnout and compassion fatigue (Ariapooran, 2014; Xu \& Song, 2016). In contrast, nurses who receive lower levels of social support tend to have higher levels of emotional exhaustion, as well as lower levels of job satisfaction (Xu \& Song, 2016). Because levels of social support have such an impact on exhaustion, burnout, and job satisfaction in nurses, it is important to consider the types of support that various groups provide them and what type is the most impactful to each individual nurse.

\section{Coworker Support}

Generally, when dealing with workplace stressors across industries, it is more likely that people within an organization will be able to provide more varied forms of support compared to 
family and friends outside of the workplace. Because of familiarity with stressors of the general workplace environment (Ellis \& Miller, 1994) and proximity (Barnett et al., 2019), coworkers are generally more likely to understand what an individual is going through and can provide more relevant forms of social support. More specifically, the work environment created for nurses is extremely important to them, and their overall well-being may be at risk in an unsupportive environment, mirrored in insufficient leadership and a lack of support from supervisors and peers (Van Der Heijden et al., 2017). With everything that nurses are responsible for, having a supportive work environment can not only impact their well-being but also their overall sense of purpose. Conte (2014) found that nurses rely on other nurses' help to assist them in discovering meaning in their work, especially in times of crisis and distress. Nurses use the connections they make with peers as opportunities for mentorship and support throughout the entirety of their career. These connections also provide psychological support, especially when nurses find themselves needing to process the frequent losses that they experience on the job (Conte, 2014). Ruiller and Van Der Heijden (2016) confirm this finding, explaining that supervisors and colleagues are often the most important source of support in time of psychological stress. Gray and Kim (2017) found that nurses will often seek emotional and instrumental support from coworkers if they feel that they cannot personally handle their own burnout. A sense of belonging to a particular group of peers means that nurses have a core support group that understands where they are coming from (Conte, 2014).

Although supervisor and coworker support are recognized as a vital part of an employee's well-being (Kossek \& Oseki, 1998), the impact of the types of support present need to be addressed as well (Hupcey, 1998). For instance, Ruiller and Van Der Heijden (2016) found that among nurses, personal support (e.g., empathy and listening to/communicating about 
personal problems) is more important than professional support (e.g. esteem, respect, and reassurance on professional skills) from direct supervisors. Personal support from supervisors was also more important than receiving support (e.g. encouragement, esteem, and protection) from colleagues. The research suggests that different variations of supervisor support are more effective than others; thus, while all types of coworker support can be beneficial, there may be some types of support and particular support providers that have a greater impact on the wellbeing of an individual nurse. It seems that general comradery and dialogue about the stressors of the job play an important role in social support among nursing staff.

\section{Family Support}

In addition to coworkers, nurses may turn to family members for social support, which is the focus of this study. While research on family social support for nurses is limited, nurses do rely on families for both action-facilitating support that focuses on child care duties and domestic chores to balance work and home life (Gifkins et al., 2017), and nurturing support in the form of esteem support to lower symptoms of burnout and compassion fatigue (Ariapooran, 2014). While these studies assessed the types of support that family members give to nurses, they each do not provide a full picture of the intersection between nursing stress and family support. More specifically, Gifkins et al. (2017) only addressed how nurses balance their work and home life and did not focus on the stress of the field, and Ariapooran (2014) did not address specific actions that family members take to facilitate support.

There is also a lack of research regarding family social support for nurses in times of high-stress and crisis. In assessing the research regarding family social support in additional high-stress jobs, gaps have come to the forefront. Research on military families heavily addresses community support given to family members (Hollingsworth, 2011), support when 
adapting back into civilian life (Hachey, 2016; Welsh et al., 2015), and support for the spouses of service members (O’Neal et al., 2020). While social support helps with emotional distress in service members (Bryan \& Hernandez, 2013), there was no differentiation in these studies among the groups (e.g., community vs. families) providing the support. In addition, research on firefighters addressed the importance of general social support in lowering PTSD symptoms and encouraging coping mechanisms (Huynh et al., 2013; Stanley et al., 2019), but these studies do not acknowledge the ways in which family members provide social support. Overall, there appears to be a lack of research pinpointing exactly how families can provide support during times of crisis to those in high-stress careers.

While research indicates that social support, regardless of who it is from, impacts burnout levels, job satisfaction, life satisfaction, and depression levels (Yildirim \& Aycan, 2008), it is important to note that not everyone will ask for support. In fact, while family members can serve as viable support for some nurses, others remove their loved ones from being available to give them support. Conte (2014) found that some nurses choose to not confide in family members about work to protect families from emotional distress. Whether they conceal distress from family members depends on the types of work experiences that nurses have. For example, some nurses who work in pediatric oncology worry that the stories related specifically to their line of work could have negative consequences on their family members (Conte, 2014). Similar to nurses, when volunteer firefighters felt exhausted with the emotional demands of the job, they also perceive that their experiences are too difficult for family members to fully understand (Huynh et al., 2013). It seems that while some nurses feel comfortable receiving social support from loved ones, others feel the need to protect them from the realities of their career. The distinction between how nurses receive social support could be the difference in how they cope, 
whether individually or communally. While social support from friends and coworkers may incorporate levels of collaboration in addressing the problem, family members may view the problem as a collective responsibility, thus enacting communal coping strategies (Rentscher, 2019).

\section{Communal Coping}

Since the late 1990s, research on communal coping has contributed to the shift in viewing coping as a unidirectional experience to viewing it as an interdependent process (Kowal et al., 2003; Lyons et al., 1998). Communal coping involves combining the resources of several people to confront hardships, meaning that a specific stressor is seen as a problem that everyone has a responsibility to combat together (Lyons et al., 1998). When stressful life events happen, they are experienced and managed both individually and in social groups, and the way that individuals experience and manage stress reveals itself through their communication habits (Lyons et al., 1998). The model created by Lyons et al. (1998), as well as a similar model created by Berg et al. (1998), provided the foundation for the communal coping model created by Afifi et al. (2006). Due to the nature of this current study, Afifi et al. (2006) provides the updated model that best fits with the discussions surrounding how nurses manage stress during the COVID-19 pandemic within the context of their familial relationships.

Similar to the original model, Afifi et al. (2006) based their model on dimensions of appraisal and action, including four different dimensions of coping with stressors. Within each dimension, individuals will determine the problem as belonging to them or to the group, as well as determine whether the responsibility of dealing with the problem falls on them or will be addressed as a group. The various forms of coping include: (1) individual coping (my problem, my responsibility), (2) protective buffering and parallelism (our problem, my responsibility), (3) 
support seeking contagion (my problem, our responsibility), directive support (your/our problem, your/our responsibility), and (4) communal coping (our problem, our responsibility) (Afifi et al., 2006). Afifi et al. (2006) expanded upon the four dimensions and asserted that families may handle communal coping in various ways. In post-divorce families specifically, they argue that the family unit may develop solutions to problems together, communicatively address the problems as if they are communally responsible, manage the problem through organization and planning, or create boundaries to protect other members of the family (Afifi et al., 2006). In addition, group dynamics can impact the coping process, and conflict may occur as group members try to decide how much responsibility each individual should have.

Because this particular model was reimagined in the context of post-divorce families, it provides a more wholistic view of what communal coping can look like among families of nurses working amidst the COVID-19 pandemic, both possibly high-stress contexts. Within the context of the COVID-19 pandemic, most families are dealing with the stress of the virus which can be interpreted as a communal stress; however, nurses may be physically isolating from family members for safety reasons or emotionally isolating by not sharing with them what they experience on the job, potentially taking the communal aspect of coping out of the equation. Thus, it is important to understand if and how nurses talk to their families about their workplace experiences and feelings to understand if they are including families in their process of coping. By utilizing communication privacy management theory in this study, I will attempt to understand the process through which nurses manage information about their jobs and the various reasons behind whether a nurse chooses to disclose private information and seek support from family members. 


\section{Communication Privacy Management Theory}

Communication privacy management (CPM) theory provides an opportunity to understand how individuals handle the ongoing tension between openness and privacy among groups and individual relationships (Petronio, 2012). CPM proposes that people characterize their private information as something that they personally own and control (Petronio et al., 2018). When someone discloses information, they do not lose ownership but instead create coowners who are also in charge of upholding the level of privacy set by the original owner (Petronio et al., 2018). A set of rules are created and consistently managed between co-owners to ensure privacy; however, sometimes conflict occurs when predetermined boundaries are crossed (Petronio et al., 2018).

\section{Suppositions of CPM}

Petronio (2002) explains five core suppositions of the theory, which are private information, privacy boundaries, control and ownership, rule-based management system, and privacy management dialectics. The first supposition, private information, explores the idea that using private information as the main part of disclosure allows for individuals to understand how intimacy and privacy are separate concepts that relate to one another (Petronio, 2002). Because self-disclosure brings intimacy to an interaction, intimacy may end up being a goal of disclosing private information with someone.

In the second supposition, privacy boundaries, Petronio (2002) discusses how boundaries play a role in the disclosure of private information. Petronio explains that having ownership over private information involves the existence of boundaries to mark ownership lines for outsiders. A collective boundary is formed between all co-owners, and rules are set up to make sure that privacy is ensured once private information is disclosed (Petronio, 2002). The boundaries set up 
in this domain are essential to making sure that the information is effectively managed by all parties (Petronio, 2010).

The third supposition, control and ownership, explores individuals' inherent need to have control over their own private information (Petronio, 2002). Due to this need to have control, individuals may decide to reveal or conceal their private information. The individual to whom the private information is being shared is granted co-ownership, leaving the disclosing individual in a more vulnerable state and granting some form of control over the private information to the receiver. The choice to reveal and conceal information comes from an individual's need to control their risk-benefit ratio by determining their willingness to experience full vulnerability (Petronio, 2002). Due to the potential liability of granting co-ownership to someone else, individuals engage in boundary control for both personal and collective boundaries. There are several levels of control present when discussing boundaries, which include: high control, moderate control, and low control (Petronio, 2002). The level of control someone has over their information predicts how selective they are in determining who knows their private information. With the information disclosure, the individual grants co-ownership to others, placing the responsibility to uphold privacy boundaries created by the original owner (Petronio \& Durham, 2008). All individuals that have access to the private information have some form of control since they are now co-owners.

The fourth supposition, rule-based management system, aids in understanding how private information is handled (Petronio, 2002). Boundary management happens on two interrelated levels, personal and collective. When personal management happens, the information is singularly owned and is controlled by the individual. Once someone shares private information, they cease to have personal-level control and engage in collective-level control with 
co-owners (Petronio, 2002). Petronio further explains that once someone makes a disclosure, they are giving the recipient the responsibility to appropriately manage the private information. Going forward, all co-owners have to regulate the management of the information. The rule management system depends of three processes: privacy rule foundations, boundary coordination, and boundary turbulence (Petronio, 2002). The first process, privacy rule foundations, represents the way rules are developed between co-owners and the properties of them. Next, boundary coordination reflects how privacy is regulated through managing collective boundaries. Lastly, boundary turbulence occurs when people are unable to work together to create a smooth coordination process and the rules become asynchronous (Petronio, 2002).

In the final supposition, privacy management dialectics, Petronio (2002) explains that there are a variety of dialectics happening in the conversation about and regulation of private information. The dialectics most present in this theory include disclosure-privacy, concealingrevealing, and openness-closedness (Petronio, 2002). There is a specific tension present in someone's decision to disclose private information with others. Because of this tension, individuals often must decide what information they want to disclose and withhold from others (Ebersole \& Hernandez, 2016).

\section{Rule-Based Management System}

The rule-based management system is important to consider when discussing CPM because individuals establish rules in order to regulate access and protect their private information (Petronio, 2002). The three rule-based management processes - privacy rule foundations, boundary coordination, and boundary turbulence - provide a well-rounded view of the regulation of private information. 
The first process, privacy rule foundations, details how privacy rules are constructed and what elements are present in each one (Petronio, 2002). When constructing the management of privacy rules, individuals utilize the criteria of gender, motivation, context, cultural expectations, and risk-benefit ratio (Petronio, 2002). For example, the cultural expectations in a hospital workplace may encourage nurses to regulate their emotions while on the clock. If nurses feel uncomfortable with violating that cultural norm, they may not engage in disclosure about their experiences with burnout in the workplace.

The second process, boundary coordination, describes how co-owners of private information regulate further disclosure boundaries (Petronio, 2002). People consistently regulate boundary coordination through boundary linkage, ownership rights, and permeability. When people share private information, the individuals in the interaction automatically become linked, regardless of the situation (Petronio, 2002). The linkage creates co-ownership of the private information and the boundaries, dictating the responsibility of the individuals involved. For instance, if nurses share their experiences with burnout with one another during a shift break, they each now have become responsible for maintaining and regulating the privacy of each person's information and the boundaries that come along with the disclosure. In addition to linkage and ownership, boundary permeability highlights the variation that comes with concealing and revealing private information (Petronio, 2002). Boundaries can range from open access to closed access.

The third process, boundary turbulence, occurs when the boundaries and rules that the individuals set up are violated (Petronio, 2002). Turbulence can either occur from a complete misunderstanding of the privacy boundaries or an intentional boundary violation (Petronio \& Caughlin, 2006). Referring to the previous example, if among the group of nurses who shared 
stories of burnout, one of the members of the group decides to share others' experiences with burnout with their supervisor, the group will experience turbulence because the boundaries were breached. When the violation is intentional, as in this example, the other nurses may feel betrayed by the individual who violated the privacy rule. Often times turbulence requires the confidants to renegotiate the privacy rules or restrict the permeability of the boundaries moving forward, in that they may reiterate the privacy rules among the group, or they may choose to stop sharing private information with the nurse who violated privacy.

\section{Privacy Management among Family Members}

Through CPM, Petronio (2002) argues that families are a clear example of how a collective group utilizes privacy roles repeatedly to form patterns of privacy choices over time. For most children, families provide the first set of experiences with privacy and societal norms (Serewicz, 2013). Parents and family members are often a child's first teachers of privacy management and provide them guidelines on privacy based on the culture of the family and society as a whole (Petronio, 2010). As families grow and develop, so do their privacy management regulations.

There are several reasons why individuals choose to disclose private information, as well as factors that impact who they choose as a confidant. Individuals may disclose to gain support or advice (Smith \& Brunner, 2017), feel better, gain reassurance, and legitimize their feelings (Pederson \& McLaren, 2016). When analyzing discourse from a pro-anorexia website, Herrman and Tenzek (2017) found that family members disclosed information to family members in order to fulfill a personal need for safety or to fulfill a relational need. If an individual feels that their health and safety are at risk, they may believe that they have no other choice than to disclose their private information to family members (Herrman \& Tenzek, 2017). In addition, an 
individual may feel that because a family member is transparent with them, they need to reciprocate that transparency within the relationship (Herrman \& Tenzek, 2017). In general, when individuals experience intense emotions due to hurtful experiences, they may feel the need to talk to someone else to cope (Pederson \& McLaren, 2016). In addition, individuals may choose to disclose to specific family members based on the characteristics of the confidant. If someone is supportive, trustworthy, and a good listener, the individual may feel more comfortable disclosing private information to that person (Pederson \& McLaren, 2016). In general, individuals are more likely to disclose information to those who are interested in hearing what they have to say (Petronio, 2002) and take in the disclosure in a nonjudgmental manner (Kelly \& McKillop, 1996).

Most relevant to this study are instances in which privacy management among families is addressed in high-stress situations (e.g. military deployment, divorce), in which disclosure may not always take place. In high-stress contexts, family members may filter the information presented to each other. Protective buffering, a strategy present within the communal coping framework previously presented, involves shielding others from information that may cause distress (Afifi et al., 2006). For example, to alleviate stress and mitigate negative interactions, children of military families screen the information they discuss about home life with the deployed parent and are more cautious about the information they share with the parent at home (Owlett, 2015). Parents in military families also conceal specific information about deployment from their children to avoid added stress (Owlett, 2015). In a similar vein, a parent's decision to remove the negative aspects of personal health information from discussions with their children may stem from a desire to protect them. Parents may believe that children are too young to 
understand the information presented, or they may aim to protect children from potentially stressful situations (Caughlin et al., 2013).

Alternately, family members in high-stress job contexts may choose to not disclose any information with other family members. For instance, female U.S military veterans reported difficulty sharing information about their mental health due to stigma and cultural barriers with civilian family members (Wilson et al., 2021). Not having an understanding of the severity of their mental health and not wanting to worry family members caused veterans to avoid the discussion (Wilson et al., 2021). The choice of Emergency Healthcare Providers (EHP) to not disclose information about their experiences on the job to family and close friends can stem from a desire to protect them (Kauer \& Keeley, 2019). The EHP may decide to keep that information private because they know the information is overwhelming to encounter and revealing information about their jobs may force them to relive the experience when answering questions (Kauer \& Keeley, 2019).

In addition, maintaining patient confidentiality and privacy during instances of disclosure may impact the information medical professionals share with family members. In 2002, the Health Insurance Portability and Accountability Act of 1996 (HIPAA) was revised, providing more regulations to protect the health information of patients, as well as define the rights of patients in relation to their health information (McCullough \& Schell-Chaple, 2013). In short, HIPAA protects all "individually identifiable health information held or transmitted by a covered entity or its business associate, in any form or media, whether electronic, paper, or oral" (United States Department of Health and Human Services, 2013, p. 3). The use and disclosure of protected health information (PHI) without someone's authorization is only permitted for 12 priority purposes (e.g., when required by law, in instances of abuse, neglect, or domestic 
violence; for workers' compensation cases) (United States Department of Health and Human Services, 2013). Most salient to this study is the policy that indicates there are no restrictions on the disclosure of health information that has been de-identified. According to the Privacy Rule:

De-identified health information neither identifies nor provides a reasonable basis to identify an individual. There are two ways to de-identify information; either: (1) a formal determination by a qualified statistician; or (2) the removal of specified identifiers of the individual and of the individual's relatives, household members, and employers is required, and is adequate only if the covered entity has no actual knowledge that the remaining information could be used to identify the individual. (United States Department of Health and Human Services, 2013, p. 4)

Using this policy as a guide, nurses are able to share information with individuals outside of their workplace if the health information is de-identified. While HIPAA limits the amount of information that nurses can share with family members, the policy described above allows for nurses to disclose information, if they so choose, without violating their code of conduct.

Presently, nurses are not included in the scholarly conversation surrounding personal disclosure with family members. As explained above, previous research, as well as the HIPAA Privacy Rule, describe the nuances of the nurse's role in upholding patient confidentiality with patient's family members and personal confidants outside of the field (Lambe, 2019; McCullough \& Schell-Chaple, 2013; Petronio \& Sargent, 2011); however, the exploration of a nurse's personal disclosure to family is extremely limited. On a daily basis, nurses experience a demanding workplace in which they experience emotional labor (Conte, 2014), compassion fatigue (Wakefield, 2000), and burnout (Marais et al., 2016). In addition, the COVID-19 pandemic has added another stressor to the lives of nurses, causing them to be fearful of getting 
infected and, in turn, infecting their loved ones (Huang et al., 2020). This present study acknowledges the complexity of the nursing role and the importance of social support in the process of coping. This study aims to understand nurses' privacy management in communication with their families and whether managing private information in particular ways may impact their ability to cope with their job. The following research questions guide the present study:

RQ1: What information emerges as salient when nurses talk about their job?

RQ2: What are nurses' reported perceptions related to privacy management with family about their jobs?

RQ3: What forms of social support, if any, do families provide nurses?

RQ4: What are nurses' reported perceptions of the role that family social support plays in nurses' ability to cope? 


\section{CHAPTER III: METHODS}

Although scholars who study interpersonal dynamics related to health traditionally rely on quantitative and postpositivist methods (Lindlof \& Taylor, 2017), a qualitative research design was the best fit for this study based on the research questions. Qualitative researchers are concerned with observing the interactions between performances and practices of human communication, which "constitute the texture of our everyday communication" (Lindlof \& Taylor, 2017, p. 5). Qualitative research is motivated by curiosity, often identified by improvisation, to understand an individual's expertise, worldview, or aspects of their culture (Lindlof \& Taylor, 2017). A qualitative research design provides a detailed account of the human experience, including conversations that participants have had with other individuals (Lindlof \& Taylor, 2017). According to Tracy (2010), quality qualitative research is marked by a worthy topic, rich rigor, sincerity, credibility, resonance, significant contribution, ethics, and meaningful coherence. Due to the complex nature of family privacy management among nurses, in-depth, qualitative interviews were the most appropriate for the current study.

\section{Participants}

I conducted in-depth qualitative interviews with 10 individuals who currently practice in the nursing field. Criterion sampling was used to ensure that all participants meet the terms of the current study (Lindlof \& Taylor, 2017). In order to qualify, participants were required to be at least 18 years old, be a currently practicing registered nurse, and feel comfortable speaking about their experiences. IRB approval was obtained before participants were recruited for the study. Participants' ages ranged from 24 to 62 . All 10 participants were female. Participants selfidentified their race, and 9 were White and one was Hispanic. Participants ranged from having one and a half to 20 years' experience as a registered nurse. In addition, participants reported 
working in pediatric oncology, the emergency department, the medical and cardiac intensive care unit, community hospice, outpatient surgery, medical/surgical oncology, school nursing, and the pediatric ER, NICU, and PICU. It is important to note that participants with more than 5 years' experience reported on experiences from previous job titles and units.

\section{Procedures}

Participants were recruited through several different avenues. First, study information was sent through my email to personal contacts and was posted to my social media profiles (e.g. Facebook, Instagram, Twitter, Snapchat). In addition, I contacted nursing programs (e.g. Mennonite School of Nursing) and healthcare centers as a source of recruitment (See Appendices A and B for recruitment materials). Participants were required to contact me through email if they wished to participate in the study. Once contacted, I responded to the participant emails with the participation requirements, the consent form (See Appendix C), and a questionnaire to document their demographic information and job history prior to attending the interview. Due to the nature of the topic, interviews could have upset participants, especially when recounting overwhelming and traumatic experiences related to their career. In order to prevent any distress to the participants, I made them aware that they could exit the interview at any time and could choose to not answer any questions presented. This protocol was explained to participants in the initial post about the study, as well as in the consent form that I asked them to read prior to the interview. I also asked if they had questions about the informed consent before we started the interview.

An informal, flexible approach was taken for the interviews by using an interview guide (Lindlof \& Taylor, 2017) rather than a structured questionnaire (McCracken, 1988). Utilizing an interview guide allowed for participants to control the direction of the interview (Lindlof \& 
Taylor, 2017) instead of treating each participant the same (McCracken, 1988). Prior to the interview, the participant completed the questionnaire regarding their demographic information and job history (e.g. What is your age? What is your gender identity? What is your race/ethnicity? How long have you been a practicing nurse? Have you had any breaks throughout your career? What units do you primarily work in? Do you have any specialty certifications?) and emailed the responses back to me (See Appendix D for pre-interview questionnaire). I began the interview by asking participants to describe their nursing career (e.g. Walk me through what a typical day looks like for you as a nurse. What does your job require you to do each day? Do you consider yourself to be on the front lines of the pandemic? On a scale of 1-5, how stressful do you consider your job to be?). The next set of questions focused on nursing stressors and how participants cope with their job (e.g. What do you do when you are feeling particularly stressed about your job? Do you talk to coworkers or friends when you are feeling stressed out about your job? When you talk to these people when stressed, what types of things do you tell them or talk about? What do you avoid talking to them about when you feel stressed?). After asking about stressors and coping strategies, participants were asked how they disclose information with family members about their job (e.g., Are there particular people you talk to in your family about your job? How much does your family know about your job? How do you decide what to tell your family members? How is the information you share influenced by HIPAA laws? When you share information with your family about your job, how do they respond? How has COVID-19 impacted what they know or do not know? What do you expect them to do with that information? Are you ever concerned that they will share your information with other family members? What reasons do you have for telling/not telling your family about parts of your job?) The last set of questions focused on the role that family members play in supporting them and 
the role that they play in their coping process (e.g., What role, if any, do your family members play in helping you cope with your job? What kind of support do they offer? Has your family offered to give you support differently since the start of the COVID-19 pandemic? What advice would you give to family members of other nurses on how to best support the nurse(s) in their family?). With the final question, I asked participants if they had anything else to add to help me understand how they talk to their job with family members or how they cope with their job. (See Appendix E for interview protocol).

The interviews lasted between 22 and 73 minutes, averaging 39.9 minutes. All 10 interviews were conducted using Zoom, a video chat format that allowed for video and audio recordings. However, only audio recordings were utilized for transcription purposes. In fact, I used the transcription function of Zoom for the initial transcript file and then later listened to the audio recording to edit the original transcript file for accuracy. Once verbatim transcripts were completed, all recordings were deleted. All participants were given pseudonyms in order to maintain confidentiality. The transcribed interviews resulted in 100 single-spaced pages.

\section{Data Analysis}

When analyzing the data, a combination of inductive analysis and deductive coding was utilized. For RQ1, thematic analysis was used to analyze the data collected from the interviews. As explained by Braun and Clarke (2006), thematic analysis is used for "identifying, analyzing, and reporting patterns within data" (p. 79). By utilizing thematic analysis, I was be able to "search for certain themes or patterns across an entire data set, rather than within a data item, such as an individual interview" (p. 81). Braun and Clarke's (2006) explanation of thematic analysis call for a six-step process which was utilized for RQ1. First, I collected and familiarized myself with the data. Next, initial codes were generated based on the topics avoided and 
discussed by participants, which came directly from the transcripts. After generating initial codes, I looked for similarities between the initial codes and grouped the initial codes into potential themes. Then I reviewed the potential themes by checking the themes in relation to both the initial codes and the data set as a whole. Once all of the themes were checked, I defined and named them.

I also used thematic analysis for RQ2, with CPM as the sensitizing framework. Utilizing the six-step process, I first conducted a thematic analysis of the data regarding the privacy management behaviors of participants. Next, Petronio's (2002) Communication Privacy Management (CPM) theory was used as a framework to make sense of the data, highlighting the parts of the theory that were most salient to the privacy management behaviors among participants and their family members. The major themes found through thematic analysis were reported using the ideas and language of the theory.

For RQ3, Cutrona and Suhr's (1994) framework of social support, which includes five major categories of social support, was used to code the data set. To understand the types of support given to participants by family members, I utilized deductive coding to categorize participant responses into the preexisting framework. Deductive coding is a top-down approach where codes are predetermined with the use of a model or framework. In completing the process, I took existing categories, read through the data, and figured out how the data fit within the categories. The categories of social support most salient to participant experiences were addressed in the final report.

Finally, RQ4's themes and categories were developed using both thematic analysis and deductive coding. Utilizing the six-step process, I first conducted a thematic analysis of the data regarding the coping behaviors of participants. Through the data analysis process, it became 
evident that Lazarus and Folkman's (1987) Transactional Model of Coping and Stress would be a helpful framework through which to make sense of parts of the data and to help assess the potential impact of familial social support on participants' ability to cope with the job. I then revisited the data to determine how nurses' responses fit within the model and used the coping categories of the model to report findings for RQ4. 


\section{CHAPTER IV: RESULTS}

\section{Topics Discussed and Avoided}

In RQ1, I asked: What information emerges as salient when nurses talk about their jobs to family members? The following section outlines the topics that nurses choose to discuss with family members, as well as the topics they avoid discussing. At the end of this section on RQ1, I provide advice from one of the participants related to sharing particular information about the job with family members.

\section{Topics Discussed}

When discussing the experiences of their job with family members, participants mentioned the following topics (most frequent to least frequent): medical situations, vague patient stories, general updates about COVID, management issues, and end of life care and family medical wishes.

\section{Medical Situations}

Most participants described giving brief explanations of various medical situations that they encounter on a daily basis, such as wound care, cancer tumor fumigations, and other procedures. For example, Reagan, a 36-year-old community hospice nurse with nine years' experience, stated, "They [her family] know what I do, and they know what my job entails, you know. They know that I'm up close and personal with death and the wound care I've had to do." While the levels of detail may vary, most participants accounted giving descriptions of medical procedures to family members.

\section{Vague Patient Stories}

In addition, most participants described telling family members about patients with whom they have worked. These stories include experiences with patient death and humorous and/or 
outlandish patient encounters. Maria, a 62-year-old outpatient surgery nurse with 17 years' experience, said, "I would share things like I lost the patient today or we thought this was wrong with the patient and we tried this and everything we tried just didn't make, they just didn't get better, I lost the patient." Participants also described recounting humorous and outlandish stories to family members. When asked about the stories she tells her family members, Mallory, a 25year-old ICU nurse with one and a half years' experience, explained that:

The stuff that I bring up is usually like funny in a way. Like oh, I had this really crazy sundowning or detoxing patient and they were all wild and blah blah blah, you know. Or I had this really difficult family member and oh my gosh you'll never believe that, like those are the types of stuff I bring up.

Participants did not go into detail about specific encounters and always left out any identifying patient information.

\section{Updates about COVID-19}

The next most discussed topic was related to the COVID-19 pandemic. Participants' families asked for details and updates about the pandemic, specifically about the patient and nurse experiences. Most participants recalled giving general updates to family members, explaining that being a nurse does not mean they have more insight about the virus than the average person. One participant, Charlotte, a 25-year-old medical-surgical oncology nurse with two years' experience, who specifically worked on a COVID-19 floor, explained her experiences working with COVID-19 patients in great detail to her family. Charlotte explained:

I was very adamant about telling them a lot of stuff that was going on. I would tell them the kinds of levels of oxygen we are seeing, the levels of illness, like just how terrified I was. And I wanted them to know how bad it was because there were so many people in 
the world saying it's just a cold, it's just the flu, and in reality, we were intubating people left and right.

While not all participants had first-hand experience working with COVID-19 patients, family members still expected them to provide answers about the virus because of their job title.

\section{Management Issues}

In addition to general patient encounters and medical experiences, participants explained management issues with family members, including topics surrounding frustrations with doctors and administration, unionizing, and poor staffing. For example, Zoe, a 27-year-old pediatric ER, NICU, and PICU nurse with five years' experience, explained, “Sometimes I feel like I choose just even general topics not about my job, specifically, but like, you know, everyone can relate to management and poor staffing, things like that." Another participant, Maria, echoed this statement by sharing:

But usually it's, it's a difficult patient or some, something really dumb that happened or administration things that aren't going well in the administration and frustrations. We're partly doctor owned and the frustration that I might have with a particular doctor, I would share that.

Several participants explained that they may choose topics such as management and staffing because most of their family members may be able to relate based on their own job experiences in other fields.

\section{Family Medical Wishes}

Only a few participants mentioned discussing medical wishes for their own family members. Participants explained that these discussions focused on potential end-of-life care and treatment wishes of their family members. Mallory explained that: 
I think a big thing that comes up a lot is since I've started working in the ICU is code status stuff. I'm like oh, I took care of a patient who, they were in a motor vehicle accident or something and they're kind of, they're, they have a mental deficit, but they're, they're still talking to me and they're telling me that they don't want to do a trach or peg, but the family wants them to. And then I'll be like, if that were to happen to you what would, what would you want? So it kind of gives me a chance to kind of talk to them about these kind of weird crazy situations and if something like that did happen like what, what would we want?

Being in the medical field appears to allow participants to bring up topics like end-of-life decisions and medical wishes to their family more naturally, giving them an opportunity to understand the desires of their family members.

\section{Topics Avoided}

On the other hand, there are many topics about which participants do not talk to family members. As explained by Bella, a 24-year-old pediatric oncology nurse with two years' experience:

All I can do is kind of reiterate just like I don't think people realize how much nurses truly hold back from saying and hold back stories. I tell a lot of stories, I talk about work a lot, but my god it hasn't even scratched the surface.

When discussing experiences of the job with family members, the participants in this study do not talk about the following topics: identifying patient information, graphic and heartbreaking parts of the job, specific details about COVID-19, and medical terminology. 


\section{Identifying Patient Information}

Most participants stated that HIPAA privacy law requires them to strip all identifying patient information in discussions outside of the workplace. For example, Adriana, a 45-year-old school nurse with 18.5 years' experience, said, “Oh yeah. Never say any names or anything like that. It's just like things that I do for certain people. Never names. Never identifying information. No way." Maria echoes this statement by explaining:

Well, I can't share much in the current job that I have. I can't because of HIPAA. You know once HIPAA came along, the things changed a lot, so I can't share the who's of my job right now.

Maria highlights the fact that removing identifying patient information in family conversations was not always regulated within the field. The laws put into place several years ago impacted the amount of information nurses can share with individuals outside of the medical field.

\section{Graphic and Heartbreaking Parts of the Job}

Several participants shared that they withhold graphic and heartbreaking aspects of their job when talking to families. Sadie, a 24-year-old ER nurse with two years' experience, expressed, “I just, you don't tell your family, you don't tell your friends about like the really horrible parts about your job." Participants shared that they choose to avoid discussing sad and heartbreaking stories, as well as stories that bring up their own personal job trauma. Bella shared:

I think when the job gets super sad like when it gets, I'm trying to think of the right word. Because honestly, some of this stuff is just truly heartbreaking, like you just don't feel good about it or feel good about what happened. Or if a kid says, or sometimes kids will just say stuff to you that absolutely breaks your heart. Or like we had one kid that was, has told his doctor a couple times now that he's not afraid to go to heaven and like that 
kind of stuff. It's like you don't, you don't want to tell people that's what you get to hear at work. And then when it gets that sad or his parents say something like that to you. Like really when it gets to that point or like, like I was saying we have some patients that pass away with us in the hospital and, those, those kinds of situations usually I won't go into detail, I say like, "Oh yeah they went home on hospice," or "They're not doing well," or "We had a patient just pass," but I won't go into because sometimes they can get really, really sad.

Related to concealing personal trauma on the job, Adriana stated:

Like if somebody died of certain things or something happened, I don't know. I just, sometimes I'm like okay, I'm not going to say too much because it might, you know, they don't need to hear that. It may be too personal or traumatic even for me to just say and then they don't need to have that information.

Some participants choose to avoid discussing the negative parts of their profession with family members. Specifically, participants avoid experiences that are sad and heartbreaking in nature and experiences that relate to their personal job-related trauma.

\section{Specific Details about COVID-19}

Some participants described how they limited some information about COVID-19 and their experiences dealing with the virus. For instance, Brenna, a 24-year-old respiratory/medicalsurgical nurse with two years' experience, stated:

And then topics I try to avoid, I remember back in the fall, we were mixed unit and just they were not, we were not supposed to be telling people we had COVID and un-COVID people next to each other. We were avoiding the topic of how the morgue got filled up 
and how we had refrigerator trucks in the parking lot we were supposed to go and use. That type of thing.

While some participants avoid certain COVID topics, others avoid answering any questions about COVID-19 from their family members. Maria, a participant who avoided discussions about the virus with family members, explained:

So I get a lot of people asking questions, general questions about COVID and because I'm a nurse they think that I should know what's going on in the hospital, you know, and or what do you think about what Dr. Fauci says. So I get a lot of questions like that and I don't answer those questions. I just, because we're so politicized right now and oddly enough, the medical community has become politicized. And I, I tend to shy away from that as much as I can. I am in the minority in my thoughts politically in my family, so I don't say a whole lot about any of that.

As evident of the stories shared above, participants base the amount of information they share with family members about the COVID-19 virus on personal discretion and experience with the virus itself.

\section{Specific Medical Terminology}

Some participants explained that they avoid discussing specific medical terminology, including procedures and disease processes, with family members. For example, Zoe explained: Or just like it's, sometimes it's like they are not going to know what you're talking about anyway, it's like why bother calling them? They're not going to know about certain disease processes and things like that so it's like what's the point?

Participants who perceive that their family does not understand the medical terminology they use may limit what they share about specific procedures and other aspects of their job. 


\section{Advice about Topic Disclosure and Avoidance}

When asked to give advice to family members of other nurses, participants discussed topics that they avoid when talking to family members. One participant, Brenna, explained that: Recognizing that like who you know as your family member is a totally different person from who they are at work, and that at work, I am like I'm 38 years old, and I have my life together, and I know what's right for your parent, and I know what I'm doing blah blah blah. And then, when I step off the floor I'm just the 24 year old kid who like is still getting like paying a ticket or like paying a fine and don't have their Internet hooked up. Yeah, that type of thing. So it is really like a night and day difference. Like I almost wish my parents or my family could see me at work cause I'm like I'm a totally different person. I deal with stuff that you'll have no idea, that type of thing in that, like, I can tell you as much as I want what I do at work, but I'm really like a different person I feel like when I'm there. It's just important to recognize that too.

The advice given by Brenna shows that nurses cannot always convey what being in their positions looks like, and at times they might not want to. When talking to family members, the topics nurses discuss and avoid depend on several factors that will be explored in RQ2.

By asking RQ1, I wanted to understand the topics that participants discussed and avoided with family members. Having a comprehensive list of the topics most salient to the experiences of nurses provides a foundation for the exploration of RQ2 and the factors that impact the management of private information among nurses and their family.

\section{Communication Privacy Management Theory}

In RQ2, I asked: What are nurses' reported perceptions related to privacy management with family about their jobs? Communication privacy management (CPM) theory provides an 
opportunity to understand how individuals handle the ongoing tension between openness and privacy among groups and individual relationships (Petronio, 2012). CPM proposes that people characterize their private information as something that they personally own and control (Petronio et al., 2018). When someone discloses information, they do not lose ownership but instead create co-owners who are also in charge of upholding the privacy rules set by the original owner (Petronio et al., 2018). A set of rules are created and consistently managed between coowners to ensure privacy; however, sometimes conflict occurs when predetermined boundaries are crossed (Petronio et al., 2018). I utilized CPM as a framework to understand the ways that participants make decisions about sharing job-related information with families, making note of the concepts that best explain the experiences of nurses and their privacy management tendencies. Most relevant to the participants' experiences appears to be the fourth supposition of the theory, the rule-based management system.

The rule-based management system aids in understanding how private information is handled on both a personal and collective level (Petronio, 2002). Once someone makes a disclosure, they are giving the recipient the responsibility to appropriately manage the private information. Going forward, all co-owners must regulate the management of the information for smooth privacy management. The rule-based management system depends on three different processes: privacy rule foundations, boundary coordination, and boundary turbulence (Petronio, 2002). The first process, privacy rule foundations, represents the way rules are developed between co-owners and the properties of them. Next, boundary coordination reflects how privacy is regulated through managing collective boundaries. Lastly, boundary turbulence occurs when people are unable to work together to create a smooth coordination process and the rules become asynchronous (Petronio, 2002). The following section details these three processes that are most 
salient to the privacy management practices of the nurses in this particular study. At the end of this section on RQ2, I provide advice from one participant related to the complexity of deciding what to share with family members.

\section{Privacy Rule Foundations}

Petronio (2002) explained that people utilize specific criteria to determine whether to disclose particular information to another person. In this study, I found that participants follow a set of criteria when deciding whether to share with families. Their criteria are the following: HIPAA privacy laws, the relationship with the family member, recipient knowledge level, recipient medical experiences, recipient comfort level with medical scenarios, the need to avoid worrying family members, the desire to protect family members, reliving experiences, and recipient responses.

\section{HIPAA Privacy Laws}

Most participants explained that HIPAA requires them to strip any personal, identifying information from the patient stories they tell individuals outside of the workplace. To uphold HIPAA laws, most participants withhold patient names when sharing patient stories and jobrelated experiences. In contrast to other participants, Teri, a 45-year- old school nurse with 20 years' experience, explained that she almost never discusses patient stories, even after removing the information about the patient. Teri said:

I have always been like crazy over the top rule follower my whole life and so I always have in my mind that I worked really hard for this license and my professionalism and all that stuff. And so I'm always worried, like I don't want to say the wrong thing or get in the wrong discussion. So when you're thinking like that, I think it hinders what you talk 
about because you don't want to have to worry about what you're saying, you know what I mean? You don't want to have to be calculated with everything you're saying. In addition to her rule-following nature, Teri's position as a school nurse in her hometown impacts the information she shares with people outside of her workplace. There is a greater chance that family members will be able to identify her patients compared to other participants like Reagan, who works in community hospice care. Thus, the patient stories the participants share are dependent on nurses' adherence to the law and their family members' ability to potentially identify patients.

\section{The Relationship with the Family Member}

Participants explained that the information they share is also based on the specific relationships. When asked if she needs to set boundaries to ensure that family members will not share information, Charlotte says that she "would never talk to somebody in my family who I felt like I would need to say that to.” Most participants echoed this statement, stating that they will only go to the family members that they trust. For example, when asked why she chooses to talk with her husband over other members of her family, Teri said:

Obviously, he's my husband, so I do, I definitely trust him more than any other person on the face of the earth. So yeah I, yes so and yeah I would assume that's why I talk to him the most. And I know I can trust him and I know that whatever is said stays between us. Participants expressed that they share based on the trust they have within the relationship. In addition, having at least one trustworthy familial confidant seems to be important to them. 


\section{Recipient Knowledge Level}

Familial knowledge of medical terminology may impact privacy management as well. In some cases, participants explained that they do not share with uninformed family members. For example, Zoe shared:

Just like it's, sometimes it's like they are not going to know what you're talking about anyway. It's like why bother telling them, they're not going to know about certain disease processes and things like that so it's like what's the point?

For some participants, taking the time to explain the background before sharing a story is not worth the extra effort. In turn, they choose not to share with the family members who may not understand what their job entails because they do not have a medical background.

While some participants explained that having family members in the medical field allows them to share more, others stated that it makes them share less. Family members having a medical background gives participants the opportunity to communicate with someone that understands their career. For example, Zoe said:

Now my sister's a nurse, so she gets it a little bit more. And because it's like before I would work night shift and people wouldn't get like you go without sleep to make it to a family event or you just kind of don't talk about what you went through at work the night before because everybody's like "Oh, my god that's so sad, how do you deal with that?". Like well it's your career, you have to deal with it. So now more so, yeah I probably talk to my sister about it because she kind of gets it more. And she even says that, she's like "Oh my god after going through it myself, I see how hard it is and I see how hard night shift is or dealing with certain patients." So I mostly talk to her, I feel like. 
Zoe has a family member confidant who understands her perspective and needs no further explanation after a difficult day. In this instance, Zoe does not need to calculate the risk of being vulnerable. According to CPM, Zoe may present low control boundaries with this person because there is not as much risk in discussing difficult job-related experiences. On the other hand, Mallory explains that she avoids conversation with family members that work on the clinical side of medicine because they shy away from difficult conversations about the toxicity of the medical field. Mallory said:

I mean I have family members that work in a hospital but they're more the clinical side, so they aren't at the bedside and it's, I would say it's almost even harder to talk to them about it than people who aren't even in the healthcare field at all because the problem is the people who are in clinical almost like make me more mad talking about this stuff because it's like you're the ones that are putting policies in place and you're so, they're just in a different world. It's not like they mean to do it, they're just in a different world. I guess the bedside nurses and the bedside staff think that they're better than the clinical people because we're the ones actually doing the hard work and, you know, oh you got to stay home during COVID must be nice, like that type of stuff. But then the, the clinical people are like, well this is how we, we need to be implementing these measures and stuff so that we can have better care for our hospital and I get where they're coming from, but it's like you, just not grounded in reality whatsoever. And so that's why it's kind of hard for me to talk about this stuff to a lot of my family members because so many of my family members are in the clinical side of the, the I guess management type stuff in the hospital. 
Mallory's statement shows that just because a family member has a medical background, does not mean that a nurse will share their job-related experiences with them. While her family members do have a better understanding of the medical terminology she references, they do not fully understand her experiences as an ICU nurse. Different from Zoe, Mallory may exhibit high forms of control when conversing with her family members because she perceives the conversations to elicit more vulnerability out of her. In turn, while some have found relief in having family members that understand their job and can communicate from personal experience, others avoid talking to family members in the medical field because they cannot relate to their own lived experience in the career.

\section{Recipient Medical Experiences}

The medical experiences of the recipient also impact the privacy management tendencies of participants. Based on personal experiences of family members, some participants choose to not tell stories that may have a negative impact on them. For example, Brenna said:

We talk every so often, mostly at me and my mom just talk on the phone. She'll call me like once a week and that type of stuff. And she's actually one person I try to avoid talking about work stuff with. Her only medical background is taking care of her mom when she was passing, so she has a pretty bad connotation with hospitals and health care in general.

Brenna avoids discussing job-related experiences with her mom because of the negative experiences she has had with healthcare in the past. Several participants explained that they choose to filter out specific information due to the specific experiences of their family members. 


\section{Recipient Comfort Level with Medical Scenarios}

Another factor that participants consider when choosing whether to disclosure about their jobs is family members' personal comfort level with medical scenarios. For example, Zoe said that:

I feel like I more so distinguish it [what to share with family] based on what I know their comfort level would be because it's like I mean, I know that say like my husband wouldn't want to hear about some kid that coded the night before, something like that. Especially having a baby of our own now. And it's the same with my parents or my other family, like they don't want to hear about these super sick kids that come in because I mean they don't want to picture their grandkids like that.

Participants like Zoe share with family members on a case-by-case basis, deciding the information to share based on everyone's comfort level. Brenna echoed Zoe's statement, explaining that her mom is someone with whom she avoids talking about her job. Brenna expressed,

So she's [mom] one person I try to avoid bringing stuff that makes her uncomfortable and it is kind of some basic stuff about my job she doesn't want to hear about. Taking people to the bathroom or a funny story about that, you know, we all got a funny poop story as a nurse. That type of thing is just not really her sense of humor, so I try to kind of dial it back, especially around her.

While some participants share based on the comfort level of individual family members, others just assume that their stories will make everyone without a medical background uncomfortable. In turn, they choose not to share information that will potentially make anyone in their family uncomfortable. For example, Brenna shared: 
Yeah just talking mainly about death and stuff may make most people who don't have a medical background super uncomfortable because we can uh, we can come off as a little bit less empathetic during that, but it's really just we see it a lot, we're used to it, we're a little desensitized to it.

Later in the interview, Brenna went on to say that:

It gets to be a little bit more burden on us, and then I tried to share that with my family a little bit. Kind of makes people uncomfortable, makes me uncomfortable just talking about it now, but yeah just the, the more serious parts. It's harder to convey to my family how much they do affect me and how much it makes, it's unpleasant to have to do that at work like it's just supposed to be my job, but I'm basically helping people die sometimes so it kind of can be stressful, at least with those aspects.

As shown by the participants, nurses either adapt based on each individual relationship or group all family members together and consider their comfort level when creating privacy rules.

\section{Worrying Family Members}

Participants also try to avoid worrying family members when talking about their job. One participant, Sadie, chooses to exclude specific information about her job when talking to her parents because she does not want to worry them. She explained, "Usually my parents, more than anyone, I kind of simplify it and almost make it sound not as bad as it is to make them less worried about me." When asked to further explain the situations that could potentially worry her parents, Sadie said:

They start to, I think, worry about, you know, where I live, and my safety, so I feel like I definitely try to downplay a little bit just so they're not so worried. And I, I know that when I very first started working at my job, it was a big adjustment from, you know, I 
never worked in the ER, I'd only ever done nursing home work up until then in health care, specifically, so it was a big adjustment. It was very scary and I would call my mom crying and just being like "Wow why is this so scary?" Then it made them worry, so much so, no, I definitely give them less to worry about is usually my goal.

At first, Sadie was more open about her experiences on the job; however, after noticing how worried her parents got, she decided to filter information out to hopefully lessen their worries.

\section{Protecting Family Members}

When discussing job-related experiences, most participants filter out the darker parts of their job to protect family members. One participant, Bella, explained:

I signed up to have those experiences and to have to hear those things and other people didn't, so I don't want to have to kind of force them into those emotions or force them to hear about those kinds of things because they didn't, they didn't agree to that. They, if they wanted to do that, they would have gone to nursing school and take the job and kind of the things so.

Bella highlights a sentiment shared by most participants about how they protect their family. In order protect family members, participants take on the responsibility of handling the negativity that comes with the job. For example, Mallory explained:

But I never really include here's how it made me feel, here's how the, it's just like oh, I took care of a patient who was in a fire. But I never really say, I never really go into it much more than that. Like that's really where I leave it and so because, because I think I have that mentality of, how do you even explain? And like it, even if I wanted to, why would I, why would I want to put that on them? 
Mallory recognizes the impact that the job can have and does not want to introduce that to her family members. In addition, when asked to explain how COVID-19 has changed what her family asks about her job, Mallory expressed:

Yeah right so it was just even then, like even the straightforward answers that they're asking me. Like they'll say, “Oh, are these patients really struggling to breathe?” Instantly what goes through your mind are your patients who are coding or, and that flashes before you and you kind of just have to be like "Yeah, they are" and you kind of have to filter it. But that's with every question that they're asking like "Oh, are you taking care of young patients?" and you're thinking about all the young patients that have died, you're thinking about all of those really traumatic things and you kind of have to filter, which is like "Yeah, I am" or "No I'm not." And so yeah they, it did kind of change the way that I talk to my family members because I think that's when that's when I first started really filtering myself. And kind of, and kind of being like this is so much. I think that's when I kind of understood the darkness of kind of what I shouldn't be talking about them, you know?

By filtering out the negative parts of her job, her family does not get an in-depth knowledge of her emotional responses and the levels of trauma that she has experienced. While this, in turn, forces her to not be completely truthful with her family, she makes these choices about disclosing to protect them from the horrors of her job. In turn, she fully takes on the trauma from the job herself. While not all participants expressed their protection tendencies to the extent that Mallory did, most echoed her statements, explaining that they filter out information so that their family will not feel the negative weight of their career. 


\section{The Desire to Avoid Reliving the Experience}

Some participants expressed that they do not want to relive their experiences by sharing them with family members. Other participants went a step further, explaining they also do not want to force family members to live their experiences because they know how it personally impacts them. When asked why she chooses to not discuss work experiences with family members, Teri expressed that:

I don't want to get into like, not that I, they would look at me like I was crazy if I talked to them about work but, but even with my husband, I would rather we watch a movie than sit and talk about how awful my day was today because I just don't feel like reliving it like. Like I'm done with it.

Mallory expands upon Teri's statement, sharing that she purposefully leaves out information to avoid forcing family members to relive the experiences with her. Mallory explained that:

It's just that, you don't want to relive it. You don't want to, when you come home from work, it's kind of time for you to get away from that stuff, so it's like why would I bring that type of stuff up? And then the other part of it is kind of like I was saying is, first of all, how do I even get them to understand what that feels like? And then, if I did want them to feel like they understand what that feels like why would I, why would I want them to go through that? And so kind of that double barrier, it's like I just don't even bother.

Both participants expressed the idea that when seeing family members after work, their main goal is not to retell the experiences that they just had and leave work experiences at work. This is a sentiment echoed in most participants' experiences. 


\section{Recipient Responses}

The responses that participants receive from recipients can also indicate how the nurses manage privacy about job information in future interactions with them. Participants explained that the first couple of responses someone has to their work disclosures determine with whom they talk about work in the future. For example, Mallory shared that:

And even who I'm talking to kind of depends on how much I'm going to share. So the first time you share something like that with one of them and you get a reaction from it, it kind of determines how you're going to talk to them in the future about it.

Another participant, Maria, expands on this idea, stating that the reactions of two separate family members impacted what she shares with them moving forward. When asked to explain what she discusses specifically with her husband, Maria said:

He didn't share half of his job with me when he got home from work, so I, I really learned as time went on that I didn't share a lot with him. He just didn't, he just didn't get it, you know? You, you rely so much on your co-workers to do that. If I did come home my husband was the kind of person that, instead of saying "I am really sorry you had such a shitty day, can I get you a glass of wine?" he was more like, "Well if you had done this, maybe that wouldn't happen."

She chose to share less and less as time went on because his reactions did not meet her expectations. In another instance, Maria said that her privacy management depends a lot on the response she gets from others. She said:

You're not going to continue to share with somebody gives you a negative response, or that always wants to change the situation around to having something to do with her. My 
sister, you know. So I definitely think that you share and get support, or you share according to what kind of support you get from others.

Maria shows that family members are sometimes unaware of the communication expectations of the nurse. When a family member does not take the time to listen or invalidates their experiences, the nurse may choose to exclude them from future work-related discussions. In turn, recipient responses may impact how much nurses are willing to share with them in the future. This communication interaction among nurses and their families leads to the next section, boundary coordination and boundary turbulence.

\section{Boundary Coordination and Boundary Turbulence}

Issues of boundary coordination and turbulence also emerged in the data. In general, some participants are more open than others; however, the family responses, as well as the factors explained above, and boundary violations can impact the participants' comfortability with sharing. Petronio (2002) explains that when people share private information, the individuals in the interaction automatically become linked, regardless of the situation. The linkage creates coownership of the private information and the boundaries, dictating the responsibility of the individuals involved. In addition to linkage and ownership, boundary permeability highlights the variation that comes with concealing and revealing private information (Petronio, 2002).

Boundaries can range from open access to closed access.

While some participants explained that they have very open boundaries with family members because of the trust they have within the relationships, others shared that the openness of their boundaries is situational. For example, Brenna said that:

I'm pretty open about what people can share. If I'm sharing something with someone it's usually I'm comfortable enough where it will be, it can be repeated or they'll remember it 
to share down the line. I'm never gonna spill dirty secrets or something that I'm super worried about. It's probably something I wouldn't keep to myself, so anything my parents really want to pass along.

Because she only shares general information with others about her job, Brenna trusts that even if her family members share the information with others, it will not violate any HIPAA regulations or her own personal boundaries. Bella echoed this statement, adding that her family's medical background adds to her trust in them respecting her boundaries. Bella explained:

I've never luckily, because my family, a lot of my family members are in the medical profession, they all kind of know the HIPAA and all of that, so they know not to share stories. I know that my parents, I think, have mentioned, like a couple of things just like oh she had like to deal with this kind of a situation or something like that. I never mind. If they want to, they can. If they don't, that's fine too. Yeah I've never really had to explicitly be like this has to stay just here. They've, they've kind of just known that already.

Having trust in the family members with whom they are sharing, as well as knowing that the information they are sharing is low risk, allows for participants like Reagan and Bella to classify their boundaries as open.

Specific situations also impact the openness of some participants. For example, especially during the COVID-19 pandemic, Charlotte described that she prefaces her experiences working in a COVID unit by saying that her family members should tell everyone they could about how serious the virus is. She was adamant about keeping those boundaries open in order to ensure the safety of others. In contrast to criteria previously discussed, Charlotte felt that sharing more about her job would lead to the potential protection of her family members. With more serious 
health crises, like COVID-19, nurses may share more graphic parts of their job as a means of protecting their families from the health issue.

While some participants expressed having open boundaries with family members, others shared that they are more closed off with family members. For example, Bella shared, "I've got a brother and sister. I usually never talked to them about it just because they really don't understand. Or if I do talk to them about it it's like I tend to like downplay it a lot." Because of their knowledge level or ability to understand her experiences, she does not see it as necessary to inform them of everything that goes on in her job. In addition, Adriana explained, "Yeah it may be too personal or traumatic even for me to just, you know, say and then they don't need to have that information." In both instances, participants develop closed boundaries with specific family members because they feel that the member will not understand what they are going through. On the other hand, Maria shared that the responses she has received from her husband makes her not want to share with him. She explained:

And I would come home at night and I would cry and my husband didn't understand. He would be like "You've got this. I don't know why you're acting like this. You've got this." And he just didn't understand the pressure that I was under.

While some participants closed off boundaries because of lack of understanding from family members, others had to close boundaries because of boundary turbulence.

Turbulence can either occur from a complete misunderstanding of the privacy boundaries or an intentional boundary violation (Petronio \& Caughlin, 2006). Often times turbulence requires the confidants to renegotiate the privacy rules or restrict the permeability of the boundaries moving forward, in that they may reiterate the privacy rules among the group, or they may choose to stop sharing private information with the specific individual who violated privacy. 
Of the participants in this study, only one (Maria) expressed the need to renegotiate privacy rules and boundaries based on violations. She said, "I have had set up boundaries in the past. I do have a family member that if you don't want it repeated, you don't tell her." In this quote, Maria is referencing her sister, who has consistently violated her boundaries regarding job experiences and personal experiences. Instead of renegotiating privacy rules, Maria decided to close off access to her sister specifically.

While most participants did not share instances of turbulence from family member boundary violations, many described how they have previously violated the boundaries that their family member held by sharing their job-related experiences. On several occasions, participants stated that family members have expressed that the participant violated the members' own personal boundary and specifically asked the participant to stop sharing. When asked to describe how her husband reacts to the stories she shares, Adriana said, "Like he'll let me talk up to a certain point and then he's like, I'm done hearing this. I don't want to hear any more of your drama." On two other occasions, participants expressed violating the boundaries of their family members. Brenna shared, "My mom will give me the "ugh BRENNA" like she gives me a little warning tone with my name on it like, okay that's nice but let's not hear anymore, that type of thing.” In addition, Reagan stated, “My oldest daughter will. You know, I don't really go into detail. She'll ask questions, I'll start answering it, but she's very good about okay, I'm done, I don't want to hear anymore." As demonstrated, some family members renegotiate their own personal boundaries with the participants because of their own comfort level with the information shared.

In these examples, it appears that family members are reluctant confidants. As explained by Petronio (2002), someone becomes a reluctant confidant when they unexpectedly become the 
recipient of private information. Being a confidant involuntarily means that the individual is linked to the discloser without their consent. Thus, the reluctant confidant may be unprepared to handle the consequences of the involuntary disclosure. As participants reported, they often share private information that family members are not comfortable with or do not want to know. In turn, participants are not only violating the boundaries of family members but also turning them into reluctant confidants. Even after considering certain factors when creating their own privacy rules and boundaries, participants recognized that they may violate the boundaries of their family members and, in turn, have to consider their own potential impact of disclosing about work.

\section{Advice about Managing Private Information with Family Members}

When asked to provide advice for family members of other nurses, Mallory expressed the complexity of sharing with family members. She said:

Ideally, I guess, to just let them [the nurse] go off. To just let them, I mean it's easy for me to say and easy for me to be like, yeah just let them have all their dark humor and let them say all this crazy stuff, but I'm sure in a way that would be kind of traumatizing for the family members too because they'd be like all my, like loved one is so mentally fucked up, you know what I mean? Like that would probably be traumatizing to let them to listen to as well. But like just letting them, I guess, just letting the family member have or the nurse have their safe space to talk about what they want to talk about. Because I think that, that's kind of the problem is that nurses see all this stuff, healthcare workers see all this stuff, and they can't really talk about it with anyone.

Her advice shows that while families would ideally create safe havens for nurses to express all of their thoughts and emotions, the nuances of those conversations make it difficult for that to be 
the reality. Comfort level, knowledge level, HIPAA laws, and several other factors impact nurses' privacy management processes with their family members.

\section{Forms of Social Support}

In RQ3, I asked: What forms of social support, if any, do families provide nurses? Initially I anticipated that COVID-19 would impact support the nurses received from family members. However, COVID did not emerge as a significant factor in support that family members provide. Support that nurses reported receiving on a regular basis reflect three of the

five major categories defined by Cutrona and Suhr's (1994): informational support, tangible aid, and emotional support. The five categories are designated to two overarching categories: actionfacilitating support and nurturing support. Action-facilitating support includes behaviors that assist another individual in managing daily tasks. The two categories under action-facilitating support are informational support (e.g. providing advice) and tangible aid (e.g. driving someone to the hospital). Nurturing support involves communicating messages that acknowledge the other person's emotions, providing companionship, and helping build self-esteem. Nurturing support includes esteem support (e.g. validating someone's self-concept), network support (e.g. connecting individuals with similar experiences), and emotional support (validating someone's feelings with heartfelt expressions). This section details the social support categories that participants primarily expressed receiving from family members, which are informational support, tangible aid, and emotional support. A brief explanation of the subtle differences in support because of the COVID-19 pandemic is included as well. At the end of this section on RQ3, I provide advice from a few participants related to the social support needs of nurses. 


\section{Action-Facilitating Support}

\section{Informational Support}

Some participants described that specific family members provided informational support to them in the forms of advice and information referrals. For example, Brenna explained that her dad gives her advice about being a more informed employee. Brenna said:

But I'll bring up stuff, especially with management. Like we've had a new management, I have a new manager in the last couple months and just the issues surrounding the old manager and stuff like that. And he [dad] would give me some advice with like, oh make sure you're documenting when you raise concerns about patient safety. So he looks out for me more in legal ways, especially with my job being something that if something happens at work I can be taken into court over seven years after something can happen. So he's always kind of thinking more long term for me.

The support that Brenna's dad gave her comes from a place of knowledge and experience, which better prepared her for the legal parts of her job. In addition, Sadie explained that her mom helps her problem-solve when she is dealing with issues at work. She said:

Sometimes it's a predicament that I think they could help me with. I know one time I had, there's a large population in the [town name here] that speaks Swahili and doesn't speak any English and they all, like this population for the majority don't have the ability to read or write, so then it's like well I'm really having a hard time providing large amounts of information to these people even with an interpreter because for an example you could be teaching a brand new diagnosed diabetic all this information all at once, but they can't read or write and they don't speak English. So I'm like I don't know how to provide this information in a way that they'll remember. And what we ended up coming up with was 
disposable, not really disposable, but just voice recorders so that we could record the interpreters so that if they, they could listen back to it if they needed to.

When participants have difficulty creating solutions on their own, specific family members step in to support them by giving advice or providing information from a place of knowledge or experience.

\section{Tangible Aid}

Participants also described the tangible aid given to them by family members, which included monetary support, household tasks, and child-care.

Monetary Support. A few participants mentioned how family members will offer to give monetary support through food purchases and gift cards. Bella explained:

Sometimes my mom will send a little bit of money and be like, "Go get yourself some food. You can use my credit card, it's fine." And I'm like "Okay." So they kind of try and find ways that way to help.

In addition, Charlotte mentioned, "And then my sisters, they, my older sister, she likes to send me the occasional Starbucks gift card. She's like, buy yourself a coffee on me." Participants' families will sometimes utilize monetary support to encourage treating themselves to something "on them."

Household Tasks. Most participants mentioned that family members, either live-in partners or extended family, will complete household tasks to provide them support. When asked to describe the support her boyfriend gives her, Charlotte stated:

Well Steven's [her boyfriend] very good about making sure I have dinner on the table, so I really appreciate that and after, I usually work two days in a row, after my second day, 
if he knows I had a really rough day, make sure is a glass of wine ready for me, which I always appreciate.

Echoing the sentiments of this statement, Maria expressed:

He [her husband] would do the yard work or he would do stuff like that because he knew at the end of my 12-hour shifts, I'd come home and I'd be exhausted. So, he would take care of kind of some of the everyday household kind of chores so that I didn't have to. The partners of these participants understood that coming home to dinner on the table and not having to do household chores was the best way to provide support to their partners after getting home from an exhausting day at work. In addition, participants explained that extended family members would step in to help out if needed. For example, Reagan said, "You know my, my dad helps out like mowing the lawn and stuff when it gets out of control. We've had rainstorms for weeks now, so if my yard is insane, he'll help me." Regardless of the completed task, participants seemed to think that family members understand the importance of providing support to them through tangible aid.

Child Care. While not all participants had young children, the few who did expressed the importance of receiving child-care as support from family members. Participants described providing child-care, even on days off, as helpful. As Zoe explained:

If I do even have the day off my parents will watch, or my sisters will watch my son, so I can even just go run to the grocery store, I can clean my house. Like I know that I can rely on them to help in the balance of work and home life.

Participants with children expressed that providing child-care on both workdays and off days is support that is necessary to them. 
While participants expressed receiving tangible aid to help them get through their days in practical ways, their family members also provided them with nurturing support.

\section{Nurturing Support}

\section{Emotional Support}

Most participants shared that they receive emotional support from family members. For some, emotional support entails phone calls to check in and ask them how they are doing; for others, emotional support means being available to validate their experiences and be present on hard days. For example, Charlotte explained, “Well, on my way home from work if I'm, if I had a really bad day, I'll give my mom a call and we'll just talk the whole ride home." Several other participants echoed Charlotte's sentiment, explaining that decompressing with family members on their ride home allows for them to receive consistent validation and praise. In addition, participants receive emotional support after coming home to their live-in partners. Being a physical presence and validating emotions is something that several participants expressed as important aspects of emotional support given to them by family members. For example, Mallory shared:

I think that my fiancé could definitely say there's nights where I'm really anxious, there's nights where I have trouble sleeping. And so, for him, just being there for me and just taking the time to just be present with me in those types of situations, like that helps. The type of emotional support that family members give participants differs based on what they need or want on particular nights when they come home.

\section{Impact of COVID-19 on Support}

While most participants expressed no change in support because of COVID-19, two participants noticed a shift in support at the start of the COVID-19 pandemic. Some of the other 
participants expressed that the pandemic did not change how they received support because they live far from family members. For those participants, most of the support from family was already happening virtually so they did not notice a shift. On the other hand, for both Reagan and Charlotte, the in-person tangible aid was not a frequent occurrence during the COVID-19 pandemic. Because Reagan sometimes relied on her parents for child-care, the pandemic made receiving this support difficult. She stated that:

So just for a while it was, you know, we would, I guess, because they would babysit my kids sometimes, so I got to see them a little bit just wasn't nearly as much and it was always very tense. I never, it was like that hyper vigilance during that time, that whole period that got everything crazy. It's like they'd come over for a couple hours, watch the kids while I ran out and did a couple visits, and as soon as I got back, they had to leave. Another participant, Charlotte, shared that before the COVID-19 pandemic, she would see her family often because they lived close to her. Charlotte explained that:

At the beginning, I would say that we were more distant. Like we only did things virtually and mom wasn't bringing over snacks and, and I wasn't seeing anybody. So I wasn't able to have the same kind of support, but as we've gotten more vaccinations and people are getting more and more comfortable, numbers are dropping, that's changed for sure.

Not everyone expressed the impact that the COVID-19 pandemic had on the ability to receive support from family members; however, a couple did highlight the impact it had on the support they received. 


\section{Advice about Forms of Social Support}

When asked to give advice to nurses' family members, several participants suggested the type of support that family members should be providing. One participant, Maria, said They just need to not try to solve the problems, empathize with them, give them a listening ear, and just validate everything what they have to say. Don't question them. You don't need to question me because, I mean, it's kind of like that with everything in life. My feelings are my feelings, I just want validation for it.

In addition, Teri expressed

I think that other family members need to ask them what they need because I think everybody's different. Some people need to talk and have somebody listen. Some people like me, myself, like I prefer, and they will listen, I'm not saying that they don't. But I never, you know, the help so that I can have some of the everyday stressors taken away because then that allows me to have some downtime. So I think that's the biggest thing. Like what do they need? Don't just assume. Ask. Like how would this help? How can I make your day better? How can I make this easier for you?

Both participants expressed the importance of both emotional support and tangible aid. In addition, they highlighted the importance of providing support that is tailored to the specific individual's needs.

\section{Impact of Social Support on Coping}

In RQ4, I asked: What are nurses' reported perceptions of the role that family social support plays in nurses' ability to cope? It is important to note that every participant varied in their explanation of the specific types of support that they need from family members. In addition, every participant expressed how their family either helped or hindered their coping 
process through the support they provided. One participant, Brenna, was able to capture a sentiment shared among most participants about how to ask for the support that will help them the most as they aimed to cope with their jobs. After asking what she wants people to do for her, Brenna explained:

That's something I've kind of had to think about. Like what am I looking for from people when I am telling them about my job? I usually can have like, if I have a really bad day, it is really just to vent and just to be like, "Wow that's crazy" or "Oh, you did a good job." Maybe I'm seeking for maybe a compliment or something to, like a test to my like, "Oh, you did the right thing." Like reassurance, that type of thing. If something I feel like was maybe my fault, I'm looking for more personal making myself feel better. Sometimes I get the like, "Oh I'm sorry" and that's it. I get that from my mom quite a bit where she just says, "Oh I'm sorry" and will change the subject of what we're talking about and that's definitely never what I'm looking for. Just the current like, "Oh that sucks," that type of thing. The problem solving is a good one for when it's a problem I might have been complaining about for a while and I'm really just stuck in it. Like well what am I going to do about this? That's something that my dad's really good at, problem solving, so that would be more for something that's been stressful for a while that maybe I'm just like oh I don't know how to make it go away it's been here a while. But for just a random day just the venting and maybe some empathy, and just looking for, looking for a little comfort from people definitely.

Brenna showcases the internal dialogue that happens among nurses regarding what they need their loved ones to do for them on a daily basis. Every participant has figured out not only what to ask for from specific family members, but what their family members may or may not add to 
their coping process. This section will detail the impact of social support on coping utilizing Lazarus and Folkman's (1987) Transactional Model of Stress and Coping. In addition, I address how, for some participants, social support does not help in the coping process. At the end of this section on RQ4, I provide advice from a few participants related to the potential impact that social support can have on coping.

\section{Transactional Model of Stress and Coping}

In the transactional model of stress and coping, Lazarus and Folkman (1987) explain that coping has two central functions: to change the terms of the problematic person-environment relationship (problem-focused coping) and to manage emotional distress (emotion-focused coping). The data indicate that participants focused on managing their emotional distress and not on the problems of their jobs. Specifically, participants discussed the impact of positive appraisal and seeking social support on their ability to cope with their emotional distress.

\section{Emotion-Focused Coping}

Positive appraisal. Positive appraisal entails receiving emotional validation from individuals to help with the coping process (Folkman \& Lazarus, 1988). For some participants, positive appraisal helps with their coping process. Bella said:

I think the biggest thing for me is just to validate what I've had to experience and go through being that child's nurse for the week or for the night or whatever it was. Cause especially on nights that you feel like the doctors don't listen to you or people are just giving you a hard time and you're seriously concerned or you are sad or whatever. Like it's nice to just have that acknowledgement from people. That like, "Hey you're doing a good job, you did the right thing." Kind of just validating what you're going through. 
Having family members validate her experiences allows for her to cope with the stress that comes with being a nurse, giving her the emotional reassurance that she needs. Positive appraisal seems to give some participants the validation they need to cope with the job.

Seeking social support. Whether it be tangible support or emotional support, seeking support from family members plays a role in the coping process. Family members help participants take their mind off the job, allowing them to leave their work-related stressors at work. In addition, doing activities with them or for them, as well as providing encouraging messages, helps participants process their emotions either with others or individually. Reagan explained that her parents are a main source of emotional support because they are so comfortable with conversations surrounding death. She heavily relies on them to process her emotions. The COVID-19 pandemic largely impacted the support they could give her, making her feel isolated and, in turn, falling into a depression because she did not have the community support and physical quality time with her family. For other participants, providing a balance of emotional support and tangible aid helps them to cope with the job. For example, Sadie expressed, "He [her boyfriend] can't do a whole lot physically to help at my job. He can just try to support me best as he can at home." Sadie described how her boyfriend provides both tangible aid and emotional support at home, giving her an opportunity to decompress at home and take her mind off work.

While some participants expressed the need for emotional support, others explained that they preferred receiving tangible support. For example, Teri said that:

I think that's my biggest struggle is that I don't necessarily need to talk things through as I just sometimes need a little help outside of work because when you're overwhelmed at work all day and drowning, for lack of a better word, and then you come home and your 
house is up for grabs and you have 45 loads of laundry and that kinda carries over and it kind of like makes your whole world chaotic. So offering to take some of that off my plate it, I mean is sometimes all the support I need because then I can decompress, I can sit on the couch for five minutes, or I can go call my best friend and we can laugh about a couple things. But if I had to come home and do a bunch of chores then that kind of takes me from being able to do that.

Here, Teri explained that she would rather people provide tangible support so that she can have time to herself to decompress and does not necessarily need that external validation from others to cope. As participants demonstrated, while family members are not always unpacking all of their job-related emotional trauma, either giving them emotional validation or providing tangible aid allows for them to have the space to process their trauma. Regardless of the type of support, seeking social support was found to be helpful in the coping process of some participants. More specifically, emotion-focused coping was utilized by participants with the assistance of their family members.

\section{Social Support Did Not Impact Coping Ability}

Other participants said that while their family supports them, there is no way for family members to actually help them cope with the job itself. The support is there, but it does not take away from the traumatic nature of the job and how it impacts nurses personally. When asked if family helps in the coping process, Mallory said:

Um, I would say no. I mean, not any, I mean not to any valuable extent because I mean it's nice that they're, like you say, they validate it and they say like oh yeah that must be hard. But as far as the real, actually processing and working through my trauma and stuff like that, not really. Because other than, other than just being there for me, obviously, that 
helps, but working through it and whatnot, no. Because like I said it's like how could you even begin to, it's like just a disconnect that, you know, in order to really work through my feelings and all of that it's almost like I need to talk with someone who has been there, done that type of situation. So and I just don't want to, you know, kind of like the theme is, how do I make them understand and then why would I?

Mallory's response exemplifies the disconnect that occurs among nurses and their family members. Some nurses choose to hide their job-related trauma in order to protect their family members and, in turn, that leads to family members' inability to be involved in the coping process. For others, providing tangible support, like child-care, allows for them to balance work and home life, but does not necessarily impact their coping with the stressors of the job and the emotions they experience. One participant, Zoe, explained that if she shared the emotional side of the job with her family, it would not help her personally cope. Zoe said that:

I don't feel like I really go to them when something actually bothered me at work, or say we had a kid die, or anything like that because I know that it's, it's not, it's not going to help them. They're just going to like, or it won't help me because they'll be more concerned about it. Like I need to vent, I don't need you to vent about it.

Zoe explained that sharing more detailed stories about patients with family members will result in them feeling concerned and sad. In turn, Zoe would have to comfort her concerned family members after sharing, instead of being able to share and gain support from them to help her personally cope. For participants similar to Zoe, sharing with family members may hinder their ability to cope. Thus, while receiving social support can be helpful some participants' coping process, others find it difficult for family members to be part of coping with the intense traumas of their job and prefer to have time to deal with it on their own. 


\section{Advice about the Impact of Social Support on Coping}

When asked to give advice to family members of other nurses, participants expressed sentiments that showcase the impact of social support on coping. Charlotte advised that:

Because everybody's so different I would probably say, asking them, checking and asking them, what do you need, what can I do, and just listening. Even if you don't understand everything that's going on because I know that I sometimes use too many medical terms when I'm talking to somebody about the frustrations of my job and nobody understands what I'm saying, but if you could just listen to it, whether you understand it or not, sometimes I just need to say it, you know.

Another participant, Zoe, shared that:

I would say just being like more open and realizing sometimes yeah, they don't necessarily want to talk. Maybe they do, but they don't want to talk to you. But like I said, it's important to be there for them in other ways. Like, like you said, it's a huge help when they're able to help you out with your home life, able to watch your kids, things like that. Sometimes you just need that little bit of a break um to even just let everything sink in with work for yourself before you can just jump back into things.

Both participants highlight the importance of understanding the needs of each individual nurse. For some, support and validation will help them cope, while other nurses need tangible aid to allow them to process on their own. 


\section{CHAPTER V: DISCUSSION}

The purposes of this study were to explore how nurses manage information regarding their work-related experiences with family members, and how, if at all, their disclosures and privacy management help them garner support and cope with their job. Currently-practicing registered nurses were asked to describe how they manage their private information and communicate with family members about their job-related experiences. In addition, participants were asked to describe the social support they received from family members and how familial communication and supports impacts their coping process. I used Petronio's (2002) Communication Privacy Management theory, Cutrona and Suhr's (1994) categories of social support, and Lazarus and Folkman's (1987) Transactional Model of Stress and Coping to analyze and categorize the data. This study's findings will be summarized followed by the research and practical implications and limitations of the study, with directions for future research.

\section{Summary of Findings}

In RQ1, I asked: What information emerges as salient when nurses talk about their jobs to family members? Participants reported discussing the following topics with family members: medical situations, vague patient stories, general updates about COVID, management issues, and end of life care and family medical wishes. Participants reported avoiding the following topics when communicating with family members: identifying patient information, graphic and heartbreaking parts of the job, specific details about COVID-19, and medical terminology.

Most participants described providing general information about their job, like the medical situations they encounter, brief patient stories, and their issues with management and staffing. In addition, some participants reported discussing the medical wishes of family members because of their experience with medicine and the death and dying process. 
Participants also shared giving general updates about the COVID-19 virus to family members since the start of the pandemic. On the other hand, regarding topic avoidance, most participants stated that HIPAA privacy laws require them to not disclose any identifying information in discussions with individuals outside of the workplace. In addition, several participants shared that they withhold the graphic and heartbreaking parts of their job. For instance, a few participants described not going into the details of a patient's passing or a patient's disclosure about not being afraid to die. Some participants also explained that they avoid discussing medical terminology, including disease processes and procedures. Finally, participants described withholding specific details about the COVID-19 virus. While one participant explained that she was required through hospital policy to withhold information about her unit's interactions with COVID-19 patients, another stated that she withheld information because of the politicization of the virus.

In RQ2, I asked: What are nurses' reported perceptions related to privacy management with family about their jobs? Most salient to the experiences of the participants in this study is the fourth supposition of the theory, the rule-based management system. I found support for nurses' experiences of privacy rule foundations, boundary coordination and boundary turbulence.

Petronio (2002) explains privacy rule foundations as the specific criteria used by people to determine disclosure decisions. When determining whether to disclose information to their family members, it was clear that participants use the following criteria: HIPAA privacy laws, the relationship with the family member, recipient knowledge level, recipient medical experiences, recipient comfort level with medical scenarios, the need to avoid worrying family members, the desire to protect family members, the desire to avoid reliving the experience, and recipient responses. 
Most participants explained that HIPAA privacy laws impact disclosure because they are required by law to strip any identifying patient information when sharing patient stories outside of the workplace. Some participants also reported that living in the area of their workplace further impacts the information. In those instances, even if all identifying information is removed, someone in their community may know the patient being discussed based on certain identifiers. Participants also expressed that they will only share with family members that they trust will not break the boundaries they set. For some, trust is so engrained in their relationships that participants do not have to reiterate boundaries. In addition, participants reported recipient knowledge level being a factor that impacts disclosure. For example, some participants choose not to engage in conversations with family members who have no knowledge of medical terminology. They do not want to take extra time to explain the background before sharing a jobrelated story. When discussing family members with medical knowledge, participants mentioned either sharing more or withholding more information from them. For some, having a family member with a medical background is helpful because they understand them and can engage in conversations about medical terms. For others, having a family member with a medical background makes them withhold information. As reported by one participant, family members on the clinical side of medicine tend to shy away from difficult conversations about the toxicity of the healthcare system.

Previous experiences with the medical system, as well as comfort level with medical scenarios also impact disclosure tendencies among participants. When family members have had negative experiences with the medical field, participants filter out information that would further harm them. In addition, participants either filter out information based on an individual family member's comfort level or on the assumption that everyone outside of the medical field will find 
discomfort in the description of medical scenarios. Participants also described excluding specific information that could potentially worry their family members. If candid conversations about job-related experiences result in worrying family members, participants will filter out potentially worrisome information in future conversations. In addition, participants reported filtering out the negative aspects of their job to protect to protect family members. Participants choose to take on the responsibility of handling the negativity that comes with the job. Participants do not want to subject family members to the horrors of the job and the trauma that they go through on a daily basis, thus taking the brunt of the negativity. Most participants also reported withholding information because they do not want to relive the experiences, as well as not force loved ones to live the experience. The main goals of some participants are to not have to retell traumatic jobrelated experiences and to not subject family members to live the trauma they experience. Finally, participants reported determining future conversations based on previous responses from family members. Participants explained that the first few responses someone has to their disclosures will determine how much they tell them in future interactions. Participants will tend to share less information with family members if they invalidate their experiences or respond negatively in the interaction.

While some participants reported being more open than others, familial responses and boundary violations, and other factors can impact also impact participants' comfortability with sharing with family members. Petronio (2002) highlights the variation of boundary permeability that comes with disclosure. For some participants, having trust in their relationships allows for them to have very open boundaries with family members. On the other hand, some participants reported that the openness of their boundaries is situational. For example, if the information being shared is considered low risk or if family members understand HIPAA laws because of a 
medical background, participants classify their boundaries as open access. Participants constructing closed boundaries reported doing so because specific family members would not understand what they are going through. In addition, participants with closed boundaries reported doing so because of instances of boundary turbulence. For example, one participant reported closing off access to a specific family member because they consistently violated boundaries regarding both personal and work-related experiences. Finally, participants detailed experiences in which family members chose to set a personal boundary with them. Some participants unintentionally violate family members' boundaries by going into too much detail about medical scenarios and moving past their personal comfort level. In turn, participants turned their family members into reluctant confidants. Participants recognized that they must consider the potential impact of disclosing work experiences to family members.

In RQ3, I asked: What forms of social support, if any, do families provide nurses? Participants garnered three types of support: informational support, tangible aid, and emotional support. Two other types of support, esteem and network, did not emerge in the data. Participants reported receiving informational support from family members through experience-based advice and information referrals. Examples of information support reported by participants include receiving advice about handling management issues, as well as engaging in problem solving conversations about work-related predicaments. Participants reported receiving tangible aid through monetary support, household tasks, and child-care. Examples of monetary support described by participants include offering to pay for food and sending pre-loaded gift cards. Household tasks reported by participants include having dinner ready upon arrival home, doing general household chores like laundry, and mowing the lawn. Lastly, participants with children expressed the importance of receiving child-care as support from family members on both 
workdays and days off. Finally, participants reported receiving emotional support from family members. For some, emotional support involves phone call check-ins to ask about how participants are feeling. For others, emotional support involves being present on difficult days and validating experiences through heartfelt expressions. While most participants reported no change in support because of the COVID-19 pandemic, a few noticed a shift in familial support. Some participants noted that there was no shift because family members already lived farther away, meaning that support was happening virtually even before the start of the COVID-19 pandemic. Other participants reported that in-person tangible aid, like child-care and dropping off food, was not as frequent once the pandemic started.

In RQ4, I asked: What are nurses' reported perceptions of the role that family social support plays in nurses' ability to cope? While participants reported utilizing emotion-focused coping, they did not detail any instances of problem-focused coping. More specifically, participants reported the impact of positive appraisal and seeking socials support on their coping process. For participants, positive appraisal comes in the form of emotional validation from family members. Receiving validation of the difficulties of the job and their abilities as a nurse from family members gives nurses the emotional reassurance they need to deal with the stress of the job. In addition, nurses reported seeking social support in the coping process. Participants varied in their reports of the impact of social support on their coping. For some, processing emotions through conversation and receiving validation from family members helps in the coping process. For others, receiving tangible aid allows for them to have the time to decompress and process emotions on their own. Finally, several participants explained that social support from family members does not impact their coping ability. While family members can often provide helpful support, their support does not lessen the traumatic nature of the job and the 
large impact the job has on nurses' well-being. Participants reported that family members are not part of unpacking and processing their trauma. In addition, participants noted that sharing more detailed stories about patients with family member will result in them feeling upset. Instead of receiving comfort regarding the traumatic parts of the job, participants sometimes have to comfort family members instead. As a result, family members often hinder participants from processing and coping.

\section{Research Implications}

There are many important conclusions that can be drawn from the data presented here. In the following sections, I will outline these conclusions which focus on recipient boundary coordination, the relationship between sharing and coping, and absence of communal coping. I will also discuss the practical implications of this study that include advice for nurses, family members, and healthcare teams.

\section{Recipient Boundary Coordination}

The fourth supposition of CPM, rule-based management system, aids in the understanding of how people handle their private information (Petronio, 2002). More specifically, the third process in the rule-based management system, boundary turbulence, occurs when an individual's previously created boundaries and rules are violated (Petronio, 2002). Turbulence either occurs from a complete misunderstanding of the predetermined boundaries or an intentional violation of the boundaries (Petronio \& Caughlin, 2006).

Pertaining to this study, my expectation was that nurses would create boundaries around job-related information that they expected family members to follow. While a few participants explained the personal and professional boundaries they created that family members violated, many participants reported violating their family members' boundaries. They note that their 
violation becomes evident when family members specifically ask them to stop sharing details of their job-related experiences. One participant, Adriana, stated, "Like he'll [husband] let me talk up to a certain point and then he's like, I'm done hearing this. I don't want to hear any more of your drama." Another participant, Brenna, said, "My mom will give me the "ugh BRENNA" like she gives me a little warning tone with my name on it like, okay that's nice but let's not hear anymore, that type of thing." Petronio (2002) explains that when an individual receives unexpected information without their consent, they can be categorized as a reluctant confidant. Participants in this study showcase this role, explaining that sharing information without consideration of the recipient's comfort may result in an unintentional boundary violation and creation of a reluctant confidant. Moving forward, the reluctant confidant may be less likely to want to receive disclosures about the nurses' work, which in turn may also impact their ability to provide support

These participants gave a voice to their family members during interviews, reporting that they need to be mindful of their family members' boundaries, as well as understand the potential impact of disclosures on family. It does appear that nurses place a lot of responsibility on themselves to be aware of the comfort levels and experiences of family members when deciding whether to share job-related information, many times placing their own emotions and needs below those of their family members. Several of the privacy rule criteria focus on the experiences and responses of the recipient (i.e., family member) and not the participant (i.e., nurse). Previous research indicates that in other high-stress situations, like military deployment, both the deployed parent and the child conceal information from the other (Owlett, 2015). In both cases, the individual chooses to conceal information to alleviate stress and mitigate negative interactions (Owlett, 2015). The boundaries are created by both sides in an attempt to create 
more positive interactions. Similar to deployed parents, nurses must conceal specific information that may add stress or instigate negative interactions with family members. Participants indicate that they consistently need to be mindful of their family members' boundaries, understanding that they may cause unwanted stress if they choose to say something that violates their boundaries. The nuances of boundary coordination and the process through which family members aim to construct boundaries around nurses' information should be further explored from family members' perspectives due to the complex nature of the communication that occurs among nurses and their family members. More specifically, the perspective of the reluctant confidant should be explored to understand the interactions present among nurses and their family members.

\section{The Relationship Between Sharing and Coping}

Through CPM, researchers have an opportunity to understand how individuals handle the ongoing tension between openness and privacy among groups and individual relationships (Petronio, 2012). When someone discloses, individuals become create co-owners with the recipient, who is also in charge of upholding the level of privacy set by the original owner (Petronio et al., 2018). Previous research indicates individuals specifically disclose private information to family members to gain support, receive advice, legitimize their feelings, and even fulfill a personal need for safety (Herman \& Tenzek, 2017; Pederson \& McLaren, 2016; Smith \& Brunner, 2017).

A primary goal of this study was to understand the role that disclosure with family plays in nurses' coping process. Acknowledging the complexity of the nursing role, as well as the importance of social support in coping, provided the foundation to potentially understand the role of the act of disclosure in coping. 
Initially, RQ2 (What are nurses' reported perceptions related to privacy management with family about their jobs?) included a second part that inquired as to nurses' perceptions of privacy management on coping ability. Throughout the process of data analysis, it became evident that there was a lack of data supporting the role that disclosure played on coping, and thus I removed the research question. While some participants reported that familial social support (e.g., emotional, tangible) and positive appraisal aided in their coping process, others reported that family members have no active part in their coping process, and in both instances, disclosure was rarely mentioned as impactful to their coping process. In fact, one participant, Zoe, shared that telling detailed information about job experiences would hinder her ability to cope. Zoe explained that sharing more detailed stories about patients to her family members would result in them feeling concerned and sad. In turn, she would have to comfort her family members and provide them support, instead of being able to openly share and gain support from them. Previous research supports this conclusion, indicating that an Emergency Healthcare Provider's (EHP) choice to conceal information from family members may stem from the desire to protect them, as well as not relive their job-related experiences (Kauer \& Keeley, 2019). In addition, female U.S. military veterans reported avoiding details regarding the severity of mental health with family members because they would not understand and would resort to worrying about them (Wilson et al., 2021). Similarly, Zoe reported that sharing detailed information about patients to family members will hinder her ability to receive support from family members because they would just worry about her. She does not want to relive her experiences or worry her family members, so she chooses to conceal information from them. Thus, even for the participants who expressed how family members aid in their coping process, the act of sharing was not part of the response. It was not the act of sharing that impacted their coping ability, as 
one might predict through CPM (e.g. disclosure as catharsis); instead, many times, nurses received social support from family even without disclosing details about work, and sometimes they actually avoided job disclosures to cope with their jobs.

\section{Absence of Communal Coping}

Communal coping involves combining the resources of several individuals to confront hardships, meaning there is joint responsibility in managing the issue (Lyons et al., 1998). Previous research on support and coping among nurses indicates that some nurses choose not to confide in family members to protect them from emotional distress (Conte, 2014). Protective buffering, a strategy present within the communal coping framework, involves shielding others from information that may cause distress (Afifi et al., 2006). This strategy was present among participants in this study, indicating protection as a factor in the creation of their privacy rules. In turn, this finding indicates that some nurses view coping as an individual process, excluding family members from their process and taking on the responsibility of addressing the problem themselves. Although previous research did not indicate that communal coping was a common occurrence among nurses and their families, I expected it to be more of a factor because of the recent shared global crisis, COVID-19.

More specifically, I expected Afifi et al.'s (2006) expanded version of the communal coping model to be relevant to nurses and their family members during the COVID-19 pandemic because it was reimagined utilizing post-divorce families as inspiration. Experiencing a collective stressor, like divorce, allows for families to communicatively address problems communally. In turn, I thought that dealing with the COVID-19 pandemic may mimic the experiences of post-divorce families, requiring nurses and their family members to address

problems as a unit and cope with the stress communally. However, participants' experiences 
supported previous research indicating that nurses choose not to share problems with family members to protect them (Conte, 2014). While a few participants shared general updates about COVID-19 with family members, they still viewed dealing with the stress of the job as their own issue. Some participants still viewed their job stress with a "my problem, my responsibility" mentality, not involving family members in their coping process. In turn, this study found that even in the midst of a global crisis, most participants still choose not to enact communal coping in order to protect loved ones from emotional distress of their job.

\section{Advice for Nurses, Family Members, and Healthcare}

The conclusions drawn from the data provide valuable information that can further the study of the relationships between disclosure, social support, and coping among nurses and their families. There are also several practical implications that include advice for nurses, family members, and healthcare teams.

As previously explained, nurses are currently working under consistent physical and emotional pressure, risking their lives while simultaneously fulfilling work-related responsibilities (Catton, 2020). Having to actively manage and suppress emotions, a phenomenon otherwise known as emotional labor, to fit into specific rules set by the organization amidst crisis can often lead to high turnover rates (Leiter \& Maslach, 1988) and burnout (Kowalski \& Vaught, 2001). The consistent turnover, inexperienced staff, and higher nurse-to-patient ratio can contribute to higher workload in nurses (Marais et al., 2016), thus perpetuating a culture that expects high quality patient care in an understaffed and constantly changing environment. Thus, nurses must find ways to manage and cope with the stress they experience daily. The findings from the present study illuminate the nuances that currently exist among disclosure, support, and the coping process in nursing. The data show that while some 
nurses may feel similarly about the field itself, disclosure tendencies, support seeking behaviors, and coping strategies vary based on the individual. Thus, while it is important to provide advice to relevant communities and institutions addressed in this study, it is equally as important to recognize that these findings should not be universally applied.

From this study, RQ2's findings demonstrate how nurses manage their private information through the creation and renegotiation of privacy rules and boundaries. Through the utilization of specific criteria, nurses can negotiate the information they choose to share and not share with family members. More specifically, nurses often take the thoughts, feelings, and experiences of family members into account when deciding what to share regarding their jobrelated experiences. In turn, nurses are not able to fully express the job-related stress and potential trauma to family members. In addition, RQ4's findings highlight that while some nurses utilize familial support within their coping process, others recognize that family members do not help and may, at times, hinder their ability to cope. Thus, it is important for both family members and healthcare teams to recognize that nurses may not share various details about their job with family members and as a result, may need to seek out other avenues to cope with the stress of the job.

The results from this study can serve as an opportunity for healthcare teams and organizations to learn the importance of providing comprehensive mental health resources for nurses. As evident in participant responses, families do not always have the emotional ability or knowledge to engage in difficult conversations about the nursing field. In addition, nurses may choose to not disclose work-related trauma with family members. In turn, they may not have an outlet to process their work-related trauma. As previously mentioned, creating an environment that requires consistent emotional labor from nurses can lead to burnout (Kowalski \& Vaught, 
2001). If nurses classify their work-environment as the cause of their stress, they may not feel comfortable going to upper-management about their issues. Thus, nurses may not have the opportunity to process and cope both in and out of the workplace. Healthcare organizations should take the findings of this study and turn it into opportunity to provide the support for nursing staff that they may not experience at home. Creating support groups, providing counseling services, and hosting workshops on developing coping skills may give nurses an outlet outside of the home to cope with the stressors of the job.

Family members can use the findings from RQ2 as an opportunity to learn how to communicate their comfort level to nurses. As evident in participant responses, nurses are not always aware of the impact that their disclosure can have on family members. To avoid becoming a reluctant confidant, family members can communicate their boundaries with the nurses in their life. Actively expressing the information they are not comfortable receiving may aid in stopping unintentional boundary violations made by nurses. In addition, the findings of RQ4 may aid in their understanding of the role they play in the coping process of their nurse family members. As evident in participant responses, families have the ability to help nurses cope, even if the coping process looks different than expected. Coping does not always have to include unpacking emotions and unloading traumatic experiences onto family members. For some nurses, taking something off their plate to allow them the opportunity to process on their own or giving them validation without requiring a lesson or explanation on their career is all they need.

For nurses, one of the most important questions to ask, as posed by Brenna, is "What am I looking for from people when I am telling them about my job?" By understanding the "why" behind sharing, as well as determining whether sharing will ultimately provide what is needed to 
cope, nurses may understand if there are benefits to sharing job-related experiences with family members. If there are no benefits to sharing with family members, it is important for nurses to cope in other ways and gain support from other individuals, which can include fellow nurses, supervisors, and even therapists. In addition, asking for support from family members does not need to mean processing trauma through vulnerable conversations and emotional validation. Support can also look like having dinner ready, mowing the lawn, and providing child-care. As evident of the various strategies discussed in Lazarus and Folkman's (1987) Transactional Model of Stress and Coping, coping is not a one-size-fits-all and requires active negotiation of needs.

\section{Limitations and Future Directions}

There are some study limitations that contribute to possible future areas of research. The primary limitations for this study include participant demographics and interview questions.

First, it is important to address the diversity of participants' demographics, including age and experience, gender identity, and race/ethnicity. Half of the participants were in their midtwenties with only one to two years' experience in the field. While these participants were able to give insight into their own job-related encounters, they could not share the depth of experience that others provided. In addition, nine out of ten participants were white and female, with one participant identifying as Hispanic and female. This predominantly white and female participant pools means that the data cannot represent the experiences of all nurses. Without input from male nurses, as well as nurses from other races and ethnicities, the results of this study are largely from a monocultural perspective. In addition, I did not collect relationship status and familial background information. Having information about who the participants live with, as well as their relationship status, could have provided more context to their experiences with loved ones. In addition, I could have made more comparisons regarding the differences that exist between 
the participants who live with others and those who live alone. In order to better understand the privacy management tendencies of nurses, other demographic information should be considered.

This study's second limitation is the construction of the interview questions. Participant responses did not fully address the construction of boundaries or perceived coping ability. In turn, the details surrounding these topics were unclear in the responses. In both instances, the construction of the interview questions could have been a factor in the lack of detailed responses. Lack of depth regarding both boundaries and coping ability provide an opportunity for future research. First, future research should explore the creation of boundaries from the perspectives of both nurses and families. More specifically, researchers should aim to understand how nurses create boundaries regarding their career with family members. In addition, scholars should interview nurses' families to better understand their reasons for setting up boundaries regarding nurse-related experiences. Finally, future research should explore how nurses cope with the stressors of their job. More specifically, if communal coping is not happening among nurses and their families, is it happening somewhere else? If nursing cohorts are perceived as "family" by some nurses, would they function similarly to how other families engage in communal coping? Future research should explore these questions and attempt to gain a better understanding of what nurses do to cope with the stressors of their job.

\section{Conclusion}

In this study, I explored the nuances of disclosure, social support, and coping present among nurses and their families. As evident in participant responses, most nurses decide what to share by taking the thoughts, feelings, and experiences of family members into account. For most, protecting family members is more of a priority than expressing their own thoughts and emotions, often hindering their ability to cope through disclosure. In addition, even if families 
want to help with the coping process, nurses may not want to engage in conversations that involve unpacking and discussing the trauma that they experience on the job. Instead, some nurses prefer receiving emotional validation and tangible aid from family members, that gives them the opportunity to take time for themselves and cope individually. While many questions remain unanswered, my findings highlight that disclosure, social support, and coping are not a one-size-fits-all among nurses and their families. Moving forward, researchers should continue to explore the potential answers to Mallory’s question, "How do I make them understand and then why would I?" from the perspectives of both nurses and their families. 


\section{REFERENCES}

Afifi, T., Hutchinson, S., \& Krouse, S. (2006). Toward a theoretical model of communal coping in postdivorce families and other naturally occurring groups. Communication Theory, 16(3), 378-409. https://doi.org/10.1111/j.1468-2885.2006.00275.x

Apker, J., Propp, K. M., \& Ford, W. S. Z. (2005). Negotiating status and identity tensions in healthcare team interactions: An exploration of nurse role dialectics. Journal of Applied Communication Research, 33(2), 93-115. https://doi.org/10.1080/00909880500044620

Ariapooran, S. (2014). Compassion fatigue and burnout in Iranian nurses: the role of perceived social support. Iranian Journal of Nursing and Midwifery Research, 19(3), 279-284.

Bai, Y., Lin, C. C., Lin, C. Y., Chen, J. Y., Chue, C. M., \& Chou, P. (2004). Survey of stress reactions among health care workers involved with the SARS outbreak. Psychiatric Services, 55(9), 1055-1057. https://doi.org/10.1176/appi.ps.55.9.1055

Barnett, M., Martin, K., \& Garza, C. (2019). Satisfaction with work-family balance mediates the relationship between workplace social support and depression among hospice nurses. Journal of Nursing Scholarship, 51(2), 187-194. https://doi.org/10.1111/jnu.12451

Berg, C. A., Meegan, S. P., \& Deviney, F. P. (1998). A social-contextual model of coping with everyday problems across the lifespan. International Journal of Behavioral Development, 22(2), 239-261. https://doi.org/10.1080/016502598384360

Braun, V., \& Clarke, V. (2006). Using thematic analysis in psychology. Qualitative Research in Psychology, 3(2), 77-101. https://doi.org/10.1191/1478088706qp063oa

Bryan, C. J., \& Hernandez, A. M. (2013). The functions of social support as protective factors for suicidal ideation in a sample of air force personnel. Suicide and Life-Threatening Behavior, 43(5), 562-573. https://doi.org/10.1111/sltb.12039 
Bureau of Labor Statistics. (2021, February 18). Occupational Outlook Handbook. https://www.bls.gov/ooh/healthcare/registered-nurses.htm\#tab-6

Bush, N.J. (2009). Compassion fatigue: Are you at risk? Oncology Nursing Forum, 36, 24-28. https://doi.org/10.1188/09.ONF.24-28

Castle, N. G., \& Engberg, J. (2006). Organizational characteristics associated with staff turnover in nursing homes. The Gerontologist, 46(1), 62-73. https://doi.org/10.1093/geront/46.1.62

Catton, H. (2020). Global challenges in health and health care for nurses and midwives everywhere. International Nursing Review, 67(1), 4-6. https://doiorg.libproxy.lib.ilstu.edu/10.1111/inr.12578

Caughlin, J. P., Petronio, S., \& Middleton, A. V. (2013). When families manage private information. In J. P. Caughlin, S. Petronio, \& A. V. Middleton (Eds.), The Routledge handbook of family communication (pp. 321-337). Routledge.

Cobb, S. (1976). Social support as a moderator of life stress. Psychosomatic Medicine, 38(5), 300-314. https://doi.org/10.1097/00006842-197609000-00003

Coetzee, S.K., \& Klopper, H.C. (2010). Compassion fatigue within nursing practice: A concept analysis. Nursing and Health Sciences, 12(2), 235-243. https://doi.org/10.1111/j.14422018.2010.00526.x

Conte, T. (2014). The lived experience of work-related loss and grief among pediatric oncology nurses. Journal of Hospice and Palliative Nursing, 16(1), 40-46. https://doi.org/10.1097/NJH.0000000000000019

Cutrona, C. (1986). Behavioral Manifestations of Social Support: A Microanalytic Investigation. Journal of Personality and Social Psychology, 51(1), 201-208. https://doi.org/10.1037/0022-3514.51.1.201 
Cutrona, C. E., \& Suhr, J. A. (1994). Social support communication in the context of marriage: An analysis of couples' supportive interactions. In B. R. Burleson, T. L. Albrecht, \& I. G. Sarason (Eds.), Communication of social support: Messages, interactions, relationships, and community (p. 113-135). Sage Publications, Inc.

Dolan, G., Strod, E., \& Hamernik, E. (2012). Why renal nurses cope so well with their workplace stressors. Journal of Renal Care, 38(4), 222-232. https://doi.org/10.1111/j.1755-6686.2012.00319.x

Ebersole, D., \& Hernandez, R. (2016). “Taking good care of our health”: Parent-adolescent perceptions of boundary management about health information. Communication Quarterly, 64(5), 573-595. https://doi.org/10.1080/01463373.2016.1176939

Edmonds, J., Kneipp, S., \& Campbell, L. (2020). A call to action for public health nurses during the COVID-19 pandemic. Public Health Nursing, 37(3), 323-324. https://doi.org/10.1111/phn.12733

Egenes, K. (2012). The nursing shortage in the US: A historical perspective. Journal of Illinois Nursing, 110(4), 18-22.

Folkman, S., \& Lazarus, R. S. (1988). The relationship between coping and emotion: Implications for theory and research. Social Science \& Medicine, 26(3), 309-317. https://doi.org/10.1016/0277-9536(88)90395-4

Freudenberger, H.J. (1974). Staff burn-out. Journal of Social Issues, 30(1), 159-165. https://doi.org/10.1111/j.1540-4560.1974.tb00706.x

Gan, Y., Liu, Y., \& Zhang, Y. (2004). Flexible coping responses to severe acute respiratory syndrome-related and daily life stressful events. Asian Journal of Social Psychology, 7(1), 55-66. https://doi.org/10.1111/j.1467-839X.2004.00134.x 
Gifkins, J., Loudoun, R., \& Johnston, A. (2017). Coping strategies and social support needs of experienced and inexperienced nurses performing shiftwork. Journal of Advanced Nursing, 73(12), 3079-3089. https://doi.org/10.1111/jan.13374

Gray, J. A., \& Kim, J. (2017). Direct care workers' experiences of grief and needs for support. Journal of Applied Research in Intellectual Disabilities, 30(6), 995-1006. https://doi.org/10.1111/jar.12339

Hachey, K. K., Sudom, K., Sweet, J., MacLean, M. B., \& VanTil, L. D. (2016). Transitioning from military to civilian life: The role of mastery and social support. Journal of Military, Veteran and Family Health, 2(1), 9-18. https://doi.org/10.3138/jmvfh.3379

Haddad L. M., Annamaraju, P., \& Toney-Butler T. J. (2020). Nursing shortage. StatPearls Publishing.

Herrman, A., \& Tenzek, K. (2017). Communication privacy management: A thematic analysis of revealing and concealing eating disorders in an online community. Qualitative Research Reports in Communication, 18(1), 54-63. https://doi.org/10.1080/17459435.2017.1294617

Hochschild, A. R. (1983). The managed heart: Commercialization of human feeling. University of California Press.

Hochschild, A. R. (2012). The managed heart: Commercialization of human feeling. University of California Press.

Hollingsworth, W. (2011). Community family therapy with military families experiencing deployment. Contemporary Family Therapy, 33(3), 215-228. https://doi.org/10.1007/s10591-011-9144-8 
Huang, L., Xu, F. M., \& Liu, H. (2020). Emotional responses and coping strategies of nurses and nursing college students during COVID-19 outbreak. Med Rxiv. https://doi.org/10.1101/2020.03.05.20031898

Hupcey, J. E. (1998). Clarifying the social support theory-research linkage. Journal of Advanced Nursing, 27, 1231-1241. https://doi.org/10.1046/j.1365-2648.1998.01231.x

Huynh, J. Y., Xanthopoulou, D., \& Winefield, A. H. (2013). Social support moderates the impact of demands on burnout and organizational connectedness: A two-wave study of volunteer firefighters. Journal of Occupational Health Psychology, 18(1), 9-15. https://doi.org/10.1037/a0030804

Kauer, T., \& Keeley, M. (2019). Conversations about death with those who experience it the most. Qualitative Research Reports in Communication, 20(1), 84-91. https://doi.org/10.1080/17459435.2019.1664622

Kelly, A. E., \& McKillop, K. J. (1996). Consequences of revealing personal secrets. Psychological Bulletin, 120(3), 450-465. https://doi.org/10.1037/0033-2909.120.3.450

Kim, M. H., Mazenga, A. C., Simon, K., Yu, X., Ahmed, S., Nyasulu, P., \& Abrams, E. J. (2018). Burnout and self-reported suboptimal patient care amongst health care workers providing HIV care in Malawi. PloS one, 13(2), e0192983. https://doi.org/10.1371/journal.pone.0192983

Kossek, E. E., \& Oseki, C. (1998). Work-family conflict, policies, and the job-life satisfaction relationship: A review and directions for organizational behavior-human resources research. Journal of Applied Psychology, 83(2), 139-149. https://doi.org/10.1037/00219010.83.2.139 
Kowal, J., Johnson, S. M., \& Lee, A. (2003). Chronic illness in couples: A case for emotionally focused therapy. Journal of Marital and Family Therapy, 29(3), 299-310. https://doi.org/10.1111/j.1752-0606.2003.tb01208.x

Kowalski, K. M., \& Vaught, C. (2001). The safety and health of emergency workers. Journal of Contingencies and Crisis Management, 9(3), 138-143. https://doi.org/10.1111/14685973.00163

Lai, J., Ma, S., Wang, Y., Cai, Z., Hu, J., Wei, N., ... \& Hu, S. (2020). Factors associated with mental health outcomes among health care workers exposed to coronavirus disease 2019. JAMA Network Open, 3(3), e203976-e203976. https://doi.org/10.1001/jamanetworkopen.2020.3976

Lake, E. T., Cordova, P. B., Barton, S., Singh, S., Agosto, P. D., Ely, B., Roberts, K. E., Aiken, L. H. (2017). Missed nursing care in pediatrics. Journal of Hospital Pediatrics, 7(7), 278384. https://doi.org/10.1542/hpeds.2016-0141

Lally, R. (2005). Oncology nurses share their experiences with bereavement and self-care. ONS News, 20(10), 4-11.

Lambe, C. (2019). Privacy in the face of pressure. Kai Tiaki Nursing New Zealand, 25(11), 3434.

Lazarus, R. S., \& Folkman, S. (1987). Transactional theory and research on emotions and coping. European Journal of Personality, 1(3), 141-169. https://doi.org/10.1002/per.2410010304

Lee, J., \& Ok, C. (2012). Reducing burnout and enhancing job satisfaction: Critical role of hotel employees' emotional intelligence and emotional labor. International Journal of Hospitality Management, 31(4), 1101-1112. https://doi.org/10.1016/j.ijhm.2012.01.007 
Leiter, M. P., \& Maslach, C. (1988). The impact of interpersonal environment on burnout and organizational commitment. Journal of organizational behavior, 9(4), 297-308. https://doi.org/10.1002/job.4030090402

Lippert, L. R., \& Hunt, S. K. (2005). An ethnographic study of the role of humor in health care transactions (Vol. 53). Edwin Mellen Press.

Lindlof, T. R., \& Taylor, B. C. (2017). Qualitative communication research methods (4th ed.). Sage Publications.

Lyons, R. F., Mickelson, K. D., Sullivan, M. J., \& Coyne, J. C. (1998). Coping as a communal process. Journal of Social and Personal Relationships, 15(5), 579-605. https://doi.org/10.1177/0265407598155001

Maslach, C., Jackson, S. E., Leiter, M. P., Schaufeli, W. B., \& Schwab, R. L. (1986). Maslach burnout inventory (Vol. 21, pp. 3463-3464). Consulting Psychologists Press.

Marais, C., Du Plessis, E., \& Koen, M. (2016). The effectiveness of sensory stimulation therapy to strengthen the resiliency of operating room nurses. Curationis, 39(1), 1-10. http://dx.doi.org/10.4102/curationis.v39i1.1590

Maunder, R., Hunter, J., Vincent, L., Bennett, J., Peladeau, N., Leszcz, M., Sadavoy, J., Verhaeghe, L. M., Steinberg, R., Mazzulli, T. (2003). The immediate psychological and occupational impact of the 2003 SARS outbreak in a teaching hospital. Canadian Medical Association Journal, 168(10), 1245-1251. Emerging Infectious Diseases, 12(12), 1924-1932. https://doi.org/10.3201/eid1212.060584 
Maunder, R. G., Lancee, W. J., Balderson, K. E., Bennett, J. P., Borgundvaag, B., Evans, S., ... Wasylenki, D. A. (2006) Long-term psychological and occupational effects of providing hospital healthcare during the SARS outbreak. Emerging Infectious Diseases, 12(12), 1924-1932. https://doi.org/10.3201/eid1212.060584

McCloskey, S., \& Taggart, L. (2010). How much compassion have I left? An exploration of occupational stress among children's palliative care nurses. International Journal of Palliative Nursing, 16, 233-240. https://doi.org/10.12968/ijpn.2010.16.5.48144

McCracken, G. (1988). The long interview (13th ed). Sage Publications.

McCullough, J., \& Schell-Chaple, H. (2013). Maintaining patients' privacy and confidentiality with family communications in the intensive care unit. Critical Care Nurse, 33(5), 77-79. https://doi.org/10.4037/ccn2013310

Melosh, B. (1982). The physician's hand: Work culture and conflict in American nursing. Temple University Press. https://muse.jhu.edu/book/9707

Miller, K. I., \& Apker, J. (2002). On the front lines of managed care: Professional changes and communicative dilemmas of hospital nurses. Nursing Outlook, 50(4), 154-159. https://doi.org/10.1067/mno.2002.126111

Miller, K., Joseph, L., \& Apker, J. (2000). Strategic ambiguity in the role development process. Journal of Applied Communication Research, 28(3), 193-214. https://doi.org/10.1080/00909880009365571

Montauk, T., \& Kuhl, E. (2020). COVID-related family separation and trauma in the intensive care unit. Psychological Trauma, 12(S1), S96-S97. https://doi.org/10.1037/tra0000839 
Moss, M., Good, V. S., Gozal, D., Kleinpell, R., \& Sessler, C. N. (2016). An official critical care societies collaborative statement: Burnout syndrome in critical care health care professionals: a call for action. American Journal of Critical Care, 25(4), 368-376. https://doi.org/10.4037/ajcc2016133

Nathaniel, A. (2002). Moral distress among nurses. Ethics and Human Rights Issue, 1(3), 3-8.

Neria, Y., DiGrande, L., \& Adams, B. G. (2011). Posttraumatic stress disorder following the September 11, 2001, terrorist attacks: A review of the literature among highly exposed populations. American Psychologist, 66(6), 429-446. https://doi.org/10.1037/a0024791

O’Brien-Pallas, L., Murphy, G. T., Samian, J., Li, X., Hayes, L. J. (2010). Impact and determinants of nurse turnover: A pan-Canadian study. Journal of Nursing Management, 18(8), 1073-1086. https://doi.org/10.1111/j.1365-2834.2010.01167.x

O'Neal, C. W., Richardson, E. W., \& Mancini, J. A. (2020). Community, context, and coping: How social connections influence coping and well-being for military members and their spouses. Family Process, 59(1), 158-172. https://doi.org/10.1111/famp.12395

Owlett, J., Richards, K., Wilson, S., DeFreese, J., \& Roberts, F. (2015). Privacy management in the military family during deployment: Adolescents' perspectives. Journal of Family Communication, 15(2), 141-158. https://doi.org/10.1080/15267431.2015.1013105

Özçevik Subaşi, D., Akça Sümengen, A., Şimşek, E., \& Ocakçı, A. (2021). Healthcare workers’ anxieties and coping strategies during the COVID-19 pandemic in Turkey. Perspectives in Psychiatric Care. 1-9. https://doi.org/10.1111/ppc.12755

Papadatou, D. (2000). A proposed model of health professionals' grieving process. Omega, 41, 59-77. https://doi.org/10.2190/TV6M-8YNA-5DYW-3C1E 
Pederson, J., \& McLaren, R. (2016). Managing information following hurtful experiences: How personal network members negotiate private information. Journal of Social and Personal Relationships, 33(7), 961-983. https://doi.org/10.1177/0265407515612242

Perry, B., Toffner, G., Merrick, T., \& Dalton, J. (2011). An exploration of the experience of compassion fatigue in clinical oncology nurses. Canadian Oncology Nursing Journal, 21, 91-105. https://doi.org/10.5737/1181912x2129197

Petronio, S. (2002). Boundaries of privacy: Dialectics of disclosure. SUNY Press.

Petronio, S. (2010). Communication privacy management theory: What do we know about family privacy regulation? Journal of Family Theory and Review, 2, 175-196. https://doi.org/10.1111/j.1756-2589.2010.00052.x

Petronio, S., \& Caughlin, J. P. (2006). Communication privacy management theory: Understanding families. In D. O. Braithwaite \& L. A. Baxter (Eds.), Engaging theories in family communication: Multiple perspectives (p. 35-49). Sage Publications. https://doi.org/10.4135/9781452204420.n3

Petronio, S., \& Durham, W. T. (2008). Communication privacy management theory: Significance for interpersonal communication. In L. A. Baxter \& D. O. Braithwaite (Eds.), Engaging theories in interpersonal communication: Multiple perspectives (pp. 309-322). Sage Publications.

Petronio, S., \& Sargent, J. (2011). Disclosure predicaments arising during the course of patient care: Nurses' privacy management. Health Communication, 26(3), 255-266. https://doi.org/10.1080/10410236.2010.549812 
Potter, P., Deshields, T., Berger, J. A., Clarke, M., Olsen, S., \& Chen, L. (2013). Evaluation of a compassion fatigue resiliency program for oncology nurses. Oncology Nursing Forum, 4O(2), 180-187. https://doi.org/10.1188/13.ONF.180-187

Rentscher, K. E. (2019). Communal coping in couples with health problems. Frontiers in Psychology, 10, 1-12. https://doi.org/10.3389/fpsyg.2019.00398

Ruiller, C., \& Van Der Heijden, B. (2016). Socio-emotional support in French hospitals: Effects on French nurses' and nurse aides' affective commitment. Applied Nursing Research, 29, 229-236. https://doi.org/10.1016/j.apnr.2015.06.006

Rushton, C., Batcheller, J., Schroeder, K., \& Donohue, P. (2015). Burnout and resilience among nurses practicing in high-intensity settings. American Journal of Critical Care, 24(5), 412-420. https://doi.org/10.4037/ajcc2015291

Serewicz, M. (2013). Introducing the special issue on communication privacy management theory and family privacy regulation. Journal of Family Communication, 13(1), 2-5. https://doi.org/10.1080/15267431.2013.743424

Shinbara, C., \& Olson, L. (2010). When nurses grieve: Spirituality's role in coping. Journal of Christian Nursing, 27, 32-37. https://doi.org/10.1097/01.CNJ.0000365989.87518.60

Smith, S., \& Brunner, S. (2017). To reveal or conceal: Using communication privacy management theory to understand disclosures in the workplace. Management Communication Quarterly, 31(3), 429-446. https://doi.org/10.1177/0893318917692896

Stanley, I. H., Hom, M. A., Chu, C., Dougherty, S. P., Gallyer, A. J., Spencer-Thomas, S., ... \& Joiner, T. E. (2019). Perceptions of belongingness and social support attenuate PTSD symptom severity among firefighters: A multistudy investigation. Psychological Services, 16(4), 543-555. https://doi.org/10.1037/ser0000240 
Suryavanshi, N., Kadam, A., Dhumal, G., Nimkar, S., Mave, V., Gupta, A., Cox, S., \& Gupte, N. (2020). Mental health and quality of life among healthcare professionals during the COVID-19 pandemic in India. Brain and Behavior, 10(11). 1-12. https://doi.org/10.1002/brb3.1837

Tracy, S. (2010). Qualitative quality: Eight "big-tent" criteria for excellent qualitative research. Qualitative Inquiry, 16(10), 837-851. https://doi.org/10.1177/1077800410383121

Tubbert, S. (2016). Resiliency in emergency nurses. Journal of Emergency Nursing, 42(1), 4752. https://doi.org/10.1016/j.jen.2015.05.016

United States Department of Health and Human Services. (2013). PCR privacy brief: Summary of the HIPAA privacy rule. https://www.hhs.gov/sites/default/files/privacysummary.pdf Van der Heijden, B., Mulder, R., König, C., \& Anselmann, V. (2017). Toward a mediation model for nurses' well-being and psychological distress effects of quality of leadership and social support at work. Medicine, 96(15). 1-6. https://doi.org/10.1097/MD.0000000000006505

Wakefield, A. B. (2000). Nurses' responses to death and dying: A need for relentless self-care. International Journal of Palliative Care, 6(5), 245-251. https://doi.org/10.12968/ijpn.2000.6.5.8926

Welsh, J. A., Olson, J., Perkins, D. F., Travis, W. J., \& Ormsby, L. (2015). The role of natural support systems in the post-deployment adjustment of active duty military personnel. American Journal of Community Psychology, 56(1), 69-78. https://doi.org/10.1007/s10464-015-9726-y 
Whitebird, R. L., Asche, S. E., Thompson, G. L., Rossom, R., \& Heinrich, R. (2013). Stress, burnout, compassion fatigue, and mental health in hospice workers in Minnesota. Journal of Palliative Medicine, 16(12), 1534-1539. https://doi.org/10.1089/jpm.2013.0202

Wilson, S., Hintz, E., MacDermid Wadsworth, S., Topp, D., Southwell, K., \& Spoont, M. (2021). Female U.S. military veterans' (non)disclosure of mental health issues with family and friends: Privacy rules and boundary management. Health Communication, 36(4), 412-423. https://doi.org/10.1080/10410236.2019.1693128

Wong, T. W., Yau, J. K.Y., Chan, C. L.W., Kwong, R. S.Y., Ho, S. M.Y., Lau, C.C., Fei, L., Lit, C. H. (2005). The psychological impact of severe acute respiratory syndrome outbreak on healthcare workers in emergency departments and how they cope. European Journal of Emergency Medicine, 12(1), 13-18. http://dx.doi.org/10.1097/00063110-20050200000005

Xu, L., \& Song, R. (2016). Influence of work-family-school role conflicts and social support on psychological wellbeing among registered nurses pursuing advanced degree. Applied Nursing Research, 31, 6-12. https://doi.org/10.1016/j.apnr.2015.12.005

Yao, X., Yao, M., Zong, X., Li, Y., Li, X., Guo, F., \& Cui, G. (2015). How school climate influences teachers' emotional exhaustion: The mediating role of emotional labor. International Journal of Environmental Research and Public Health, 12(10), 1250512517. https://doi.org/10.3390/ijerph121012505

Yildirim, D., \& Aycan, Z. (2008). Nurses' work demands and work-family conflict: a questionnaire survey. International Journal of Nursing Studies, 45(9), 1366-1378. http://dx.doi.org/10.1016/j.ijnurstu.2007.10.010 
I am a graduate student in the School of Communication and am conducting a research study to better understand how nurses make decisions about whether and how to talk to their families about their jobs for my master's thesis. If you are a currently practicing registered nurse, are comfortable speaking about your experiences, and are at least 18 years old, then I request your participation.

The interview may take place via phone or Zoom, taking approximately 45-60 minutes. The interview will be completely confidential, and I will not share your identity or anything you say to others in a way that will identify you. Throughout the interview process, you may decide not to answer any question, and you can stop the interview at any time. With your permission, I will audio record the interview and I will delete the recording once I transcribe the interview. I will also change your name on the final paper for this project.

Please direct any questions and/or comments to my thesis advisor, Dr. Aimee Miller-Ott (aeott@ilstu.edu), or to me.

If you would like to participate, please contact me at the e-mail address below. In addition, please send along this information to others and they can contact me directly to participate.

Sincerely,

Madeline (Maddie) Witt

Graduate Student, School of Communication

Illinois State University

mkwitt3@ilstu.edu 


\section{APPENDIX B: SOCIAL MEDIA RECRUITMENT POST}

Hello! I am currently conducting research for my Master's Thesis to better understand how nurses make decisions about whether and how to talk to their families about their jobs. I am conducting this research under the supervision of Dr. Miller-Ott in the School of Communication at Illinois State University. If you have a moment to spare, I would appreciate any and all volunteers willing to sit down for a 45-60 minute phone or Zoom interview.

To participate, you have to be a currently practicing registered nurse, be comfortable speaking about your experiences, and be at least 18 years old. The interview will be completely confidential, and I will not share your identity or anything you say to others in a way that will identify you. Throughout the interview process, you may decide not to answer any question, and you can stop the interview at any time. With your permission, I will audio record the interview and I will delete the recording once I transcribe the interview. I will also change your name on the final paper for this project.

Please email me at mkwitt3@ilstu.edu if you would like to participate. Please send along this information to others and they can contact me directly to participate. 


\section{APPENDIX C: INFORMED CONSENT}

\section{Dear participant,}

I am a graduate student under the direction of Professor Aimee Miller-Ott in the School of Communication at Illinois State University. As part of the program requirement, I am conducting my thesis to better understand how nurses make decisions about whether and how to talk to their families about their jobs.

To participate, you must be a currently practicing registered nurse, feel comfortable discussing your experiences, and be at least 18 years old. You are ineligible to participate if you are currently located in the European Economic Area. By contacting me to be interviewed, you are consenting to participate in this study. Additionally, you can print this form for your records. Your participation in this study is voluntary. You may skip or refuse to answer questions if you feel uncomfortable, and if you choose not to participate or to withdraw from the study at any time, there will be no penalty.

By participating in this study, you may gain valuable insights into how you manage information with family members, as well as how social support from your family plays a role in your ability to cope with your job.

Your participation will involve an open-ended interview about how you communicate about your experiences as a nurse. Prior to the interview you will complete a pre-interview questionnaire, which will include general demographic questions. This questionnaire will take about 5-10 minutes depending on the length of your responses. You will send me an email response with the answers to the questions before your scheduled interview time. Your answers will be linked to your interview responses. The interview will be conducted over the phone or through Zoom and will take approximately 45 to 60 minutes. Since the interview may be video recorded, you may turn off your video if you do not wish to be video recorded. The interview will be audio recorded, with your permission, to ensure accuracy of recording your responses.

Due to the nature of the content you will potentially be sharing, a professional risk of participating in this study could be incurring negative consequences if a coworker or supervisor were to identify you and what you have shared. To alleviate that risk, recordings will be erased after transcription and will not have any link to your identity in the digital files. I will also change any identifying information about your place of work, as well as coworker and supervisor identity in the transcripts and final report. I will use all reasonable efforts to keep any provided personal information confidential. All of your responses will be kept on a password protected laptop that only I have access to. Information that may identify you or potentially lead to reidentification will not be released to individuals that are not on the research team. However, when required by law or university policy, identifying information may be seen or copied by authorized individuals.

Your responses will be joined with those of other participants to develop themes for research presentations at conference or in publication. After your data has been deidentified, your data may also be used in other research projects.

As a participant, you may experience discomfort when talking about personal experiences. If you are distressed, you may contact Student Counseling Services at (309) 438-3655. If you are not an 
ISU student, you may call the Substance Abuse and Mental Health Services Administration (SAMHSA) at 1-800-662-HELP (4357).

Please direct any questions and/or comments to Dr. Aimee Miller-Ott (aeott@ilstu.edu) or myself (mkwitt3@ilstu.edu). If you have any questions about your rights as a subject/participant in this research, or if you feel you have been placed at risk, you can contact the Research Ethics \& Compliance Office at Illinois State University at (309) 438-5527.

Sincerely,

Madeline (Maddie) Witt, Graduate Student, School of Communication

Illinois State University

$\underline{\text { mkwitt3@ilstu.edu }}$ 


\section{APPENDIX D: PRE-INTERVIEW QUESTIONNAIRE}

Please fill out this questionnaire before the scheduled interview. You will provide general demographic information, as well as your job history. This will take you about 5-10 minutes, depending on the length of your responses.

1. What is your age?

2. What is your gender identity?

3. What is your race/ethnicity?

4. How long have you been a practicing nurse?

5. Have you had any breaks throughout your career?

6. What units do you primarily work in?

7. Do you have any specialty certifications? 


\section{APPENDIX E: INTERVIEW PROTOCOL}

Thank you for agreeing to participate in my study. The purpose of this study is to better understand how nurses make decisions about whether and how to talk to their families about their jobs. I am going to ask you a series of open-ended questions regarding your experiences as a nurse, specifically addressing how you communicate with family about your job. Just as a reminder, if you feel uncomfortable answering anything, you can skip the specific question or stop the interview.

First, I'd like to ask you some general questions about your job.

1. Walk me through what a typical day looks like for you as a nurse. (Probes: What does your job require you to do each day? Has that changed over time? How has that changed since the pandemic began?)

2. How much do you consider yourself to be on the "front lines" during this pandemic? (Probes: What do you consider to be "front line" work? Did you work directly with COVID patients?)

3. On a scale of $1-5$, how stressful do you consider your job to be (with 5 being very stressful and 1 being not at all stressful)? (Probes: Has that changed since the pandemic started?)

4. Please explain what you consider to be stressful about your job.

Now I'd like to move on to the next set of questions, which address how you manage stress with the job.

5. What do you do when you are feeling particularly stressed about your job?

6. Do you talk to coworkers or friends when you are feeling stressed out about your job? (Probes: Why do you go to those particular people? Why not others?)

7. When you talk to coworkers or friends when stressed? (Probes: What types of things do you tell them or talk about? What do you do with them to make you feel less stressed?)

8. What do you avoid talking to them about when you feel stressed? Anything you intentionally hold back from talking about with them? If so, what and why?

Now I'd like to ask you about your family and how you talk to them about your job.

9. Are there particular people you talk to in your family about your job? If so, who and why do you talk to them and not others?

10. How much does your family know about your job? (Probes: Do you talk about it every day with them? Do you only talk to certain people about it and why? Who do you leave out and why?)

11. What do family members tend to ask you about in reference to your job?

12. How do you decide what you tell your family members about your job? (Probes: How is the information you share influenced by HIPAA laws?)

13. When you share information with your family about your job, how do they respond?

14. What do you expect them to do with that information? (Probes: provide you emotional support, help you solve the problem, talk through ideas with you, etc.) 
15. Are you ever concerned that they will share your information with other family members? (Probes: Do you ever tell them what to do with the information, like "Don't tell so and so", or "Just keep that between us"? If so, why? If not, why not?)

16. What reasons do you have for telling your family what you do about your job?

17. Is there anything about your job that your family doesn't know? If so, what do they not know?

18. What reasons do you have for not telling your family about parts of your job?

19. Do you ever have concerns about talking to your family about your job? (Probes: Why do you think you have these concerns?)

20. How has COVID impacted how you communicate with your family about your job? (Probes: What do you tell or not tell them?)

In the final section of questions, I'm going to ask you focus on the impact of family support on your ability to cope with your job.

21. What role, if any, do your family members play in helping you cope with your job? (Probes: Are there particular people who help you feel better or help you cope?)

22. What kind of support do they offer? Is there anything they do or say? (Probes: For instance, do they do things like household chores so that you don't have to worry about it when you get home or do they send you encouraging messages when they know you've had a difficult week?)

23. Has your family offered to give you support differently since the start of the COVID-19 pandemic? (Probes: Do you feel that the support they have given you this past year helped you cope with the pandemic? Or has it hindered your ability to cope?)

24. What advice would you give to family members of other nurses on how to best support the nurse(s) in their family? (Probes: Does that advice change now that we are in the middle of a pandemic? And if so, how?)

25. Anything else you would like to add to help me understand how you talk about your job with your family members or how you cope with your job? Is there anything we didn't cover during our interview? 